Article

\title{
Changes and Distribution of Modes of Occurrence of Seventeen Potentially-Hazardous Trace Elements during Entrained Flow Gasification of Coals from Ningdong, China
}

\author{
Yuegang Tang ${ }^{1, *(\mathbb{D})}$, Xin Guo ${ }^{1}$, Xi Pan ${ }^{1}$, Robert B. Finkelman ${ }^{2, *}\left(\mathbb{D}\right.$, Yafeng Wang ${ }^{1}$, \\ Binbin Huan ${ }^{1}$ and Shaoqing Wang ${ }^{1}$ \\ 1 College of Geoscience and Surveying Engineering, China University of Mining and Technology (Beijing), \\ Beijing 100083, China; guoxin012370@163.com (X.G.); zhaoye2016sy@163.com (X.P.); \\ yfwang1002@163.com (Y.W.); Xikehuanbin@163.com (B.H.); wangzq@cumtb.edu.cn (S.W.) \\ 2 Department of Geosciences, The University of Texas at Dallas, 800 West Campbell Rd, R0C21, \\ Richardson, TX 75080-3021, USA \\ * Correspondence: tyg@vip.163.com (Y.T.); bobf@utdallas.edu (R.B.F.); Tel.: +86-10-62331902 (Y.T.)
}

Received: 16 March 2018; Accepted: 24 April 2018; Published: 8 May 2018

\begin{abstract}
In order to reveal the migration of trace elements from coal to gasification residues, the modes of occurrence of potentially-hazardous trace elements (Be, V, Cr, Co, Ni, Cu, Zn, As, Se, Mo, Cd, $\mathrm{Sb}, \mathrm{Ba}, \mathrm{Hg}, \mathrm{Tl}, \mathrm{Pb}$, and $\mathrm{U}$ ) were determined by a five steps sequential chemical extraction procedure. Samples were collected from a coal-to-methanol plant (GE water-slurry coal gasification, formerly Texaco) and a coal-to-olefins plant (Gaskombimat Schwarze Pumpe pulverized coal gasification, GSP) in the Ningdong Energy and Chemical Industry Base, China. Concentrations of As and Se were determined using atomic fluorescence spectrometry (AFS). The content of $\mathrm{Hg}$ was determined using a DMA-80 mercury analyzer. Other trace elements $(\mathrm{Be}, \mathrm{Cr}, \mathrm{Co}, \mathrm{Ni}, \mathrm{Cu}, \mathrm{Zn}, \mathrm{Mo}, \mathrm{Cd}, \mathrm{Sb}, \mathrm{Ba}, \mathrm{Tl}, \mathrm{Pb}$, and $\mathrm{U}$ ) were analyzed using inductively-coupled plasma mass spectrometry (ICP-MS). XRD and SEM-EDX were employed to determine the minerals or other inorganic phases in samples. The modes of occurrence of trace elements in feed coals can influence their behavior, including their volatility during coal gasification and, ultimately, the element's mode of occurrence in the gasification residues. Knowing an element's mode of occurrence in the feed coal may aid in anticipating which components the elements are likely to combine with during liquid slag cooling. Based on the relative enrichment of trace elements in the residues, elements $\mathrm{Be}, \mathrm{V}, \mathrm{Cu}, \mathrm{Mo}, \mathrm{Ba}$, and $\mathrm{Hg}$ showed volatility during the GE and GSP gasification processes; As and Se showed volatilization-condensation behavior during the GE and GSP gasification processes; $\mathrm{Cr}, \mathrm{Ni}, \mathrm{Zn}, \mathrm{Cd}, \mathrm{Sb}, \mathrm{Tl}, \mathrm{Pb}$, and $\mathrm{U}$ showed volatility during the GE gasification process; $\mathrm{Zn}, \mathrm{Cd}, \mathrm{Sb}, \mathrm{Pb}$, and $\mathrm{Tl}$ in the GSP samples, as well as $\mathrm{Co}$ in the GE samples, showed volatilization-condensation behavior; and $\mathrm{Cr}, \mathrm{Co}, \mathrm{Ni}$, and $\mathrm{U}$ showed less volatility during the GSP gasification process. In the gasification residues, quartz, calcite, and Al-Si glass were the main inorganic phases, carbonates and iron and manganese oxides (likely recrystallized calcite) were the main hosts of most trace elements in the residues, including $\mathrm{Be}, \mathrm{V}, \mathrm{Cr}, \mathrm{Co}, \mathrm{Ni}, \mathrm{Zn}, \mathrm{As}, \mathrm{Cd}, \mathrm{Ba}, \mathrm{Hg}$, $\mathrm{Tl}, \mathrm{Pb}$, and $\mathrm{U}$. Copper, $\mathrm{Zn}, \mathrm{Se}, \mathrm{Cd}$, and $\mathrm{Sb}$ tended to stay in the Al-Si glass. Molybdenum is likely precipitated with the sulfides in the residues.
\end{abstract}

Keywords: coal gasification residues; hazardous trace elements; sequential extraction; modes of occurrence 


\section{Introduction}

Utilizing coal cleanly and effectively will be increasingly important as countries try to reduce environmental impacts caused by coal use [1]. Compared with coal combustion, coal gasification is a less polluting form of coal use and aims for "zero emissions" [2]. The "zero emissions" means that trace elements in coal are not released to air directly during coal gasification due to the closed gasification system. However, the gasification process does produce a very large amount of solid residues which contain various trace elements that may cause environmental problems [3]. Trace elements migrate into the coarse gasification residue (similar to bottom ash in coal combustion) and fine residue (like fly ash in coal combustion) unevenly in gasifiers due to the properties of the feed coal and the gasification conditions [4-6].

Coal is a complex heterogeneous mixture of organic and inorganic constituents [7]. Organic matter and minerals will be destroyed by high-temperature gasification $\left(1250-1450{ }^{\circ} \mathrm{C}\right)$. Some of the trace elements (such as Be, As, Se, and $\mathrm{Hg}$ ) associated with the organic matter or in the sulfides tend to vaporize [5] and then condense on the finer particles which have relatively high surface areas [6,8-11]. whereas the more volatile trace elements (such as $\mathrm{F}, \mathrm{Cl}, \mathrm{Br}$, and $\mathrm{Hg}$ ) will be released into the gas phase. The non-volatile elements (such as $\mathrm{Sc}, \mathrm{Mn}, \mathrm{Rb}, \mathrm{Zr}, \mathrm{Hf}$, rare earth elements, and Th) will be concentrated in the solid gasification residues [6,12]. Currently, gasification residues are buried in landfills and there is no valid way to use them, which differs from the systematic utilization of coal fly ash [13-16]. Thus, trace elements enriched in the residues, especially hazardous elements, may result in contamination of soil or ground water. Numerous investigations [17-20] indicate that the modes of occurrence of trace elements in feed coals are the key factor affecting its partitioning behavior during coal utilization. Nordberg and Nordberg [21] used chemical methods to determine the modes of occurrence of trace elements and to measure lower concentrations then was common. They emphasized that future research using modern chemical methods will focus more on elemental speciation and on measuring lower trace element concentrations. On the other hand, critical elements in coal in some cases could be concentrated in gasification residues due to their high concentrations in raw feed coals [22,23] and, thus, could be potential sources for critical element industrial extraction and utilization [24].

Previous investigations on trace elements have been mostly qualitative due to the complexity of their modes of occurrence [8,11]. It is difficult to quantitatively determine the modes of occurrence of trace elements in coal, especially when the elements are present in low concentrations [18]. Many findings about the behaviors of trace elements during thermo-chemical conversion of coal are mostly based on lab-scale simulation, theoretical thermodynamic equilibrium, and stoichiometric calculating tools (modeling) [25-31]. These lab-scale simulation or modeling investigations may be inaccurate for predicting partitioning of trace elements in a real, complicated coal-transformation system. Sequential chemical extraction is another important method to determine the modes of occurrence of trace elements, especially following float/sink testing of coal [32]. Dai et al. [33] combined density separation testing and sequential chemical extraction to study the modes of occurrence of $\mathrm{U}$ and Th in six stages, including water soluble and exchangeable (extracted by deionized water) forms, ion-exchangeable speciation (extracted by ammonium acetate), organic associated elements (determining supernatant solution separated by tribromethane), carbonates (extracted residual solid from last stage), silicates (extracting supernatant solution from density separation from tribromethane using hydrofluoric acid and concentrated nitric acid), and sulfides (extracted by concentrated nitric acid). This sequential chemical extraction procedures then adopted by Liu et al. [34] to study the modes of occurrence of trace elements in the superhigh-organic-sulfur coals. Riley et al. [19] studied the modes of occurrence of twenty trace elements (Be, B, Cr, Co, Mn, Ni, Cu, Zn, As, Mo, Cd, Sb, $\mathrm{Hg}, \mathrm{Tl}, \mathrm{Pb}, \mathrm{Bi}$, Th, and $\mathrm{U}$, as well as the minor elements $\mathrm{S}$ and $\mathrm{Fe}$ ) in Australian coal in six stages, including water-soluble and exchangeable (extracted by deionized water) forms, ion-exchangeable speciation (extracted by ammonium acetate), carbonates, oxides and monosulfides (extracted by hydrochloric acid), bisulfides (extracted by concentrated nitric acid), silicates (extracted by a mixture of hydrofluoric acid and hydrochloric acid), and organic associated elements (determined in the residual 
solid). Spears [35] investigated the mode of occurrence of trace elements in fly ash using laser ablation inductively-coupled plasma mass spectrometry and indicated that glass in the ash is an important host for $\mathrm{V}, \mathrm{Cu}$, and $\mathrm{Zn}$ and that $\mathrm{Cr}$ and $\mathrm{V}$ appeared to be concentrated in both the glass and the magnetite components. Spears [36] then determined the trace element distribution using a statistical analysis of the data from the sequential chemical leaching results. Finkelman et al. [37] used sequential leaching with ammonium acetate, hydrochloric acid, hydrofluoric acid, and nitric acid to quantify the modes of occurrence of 42 elements in 20 coal samples. A recent study by Liu et al. [38] investigated non-mineral inorganics in low rank coals by sequential leaching, using water, ammonium acetate and $\mathrm{NH}_{4}-\mathrm{EDTA}$.

However, to our knowledge the study of the modes of occurrence of trace elements in gasification residues has not been attempted. The objective of this investigation is to determine the modes of occurrence changes and distribution of trace elements during two different commercial-scale entrained flow coal gasification processes in China. The results may be useful in anticipating possible economic by-product recovery potential and possible environment and human health impacts.

\section{Materials and Methods}

\subsection{Studied Samples}

Seven samples consisting of two feed coals (designated as GE-C and GSP-C) and five corresponding residues (three coarse residues, designated as GE-CR-A, GE-CR-B, and GSP-CR, and two fine residues, designated as GE-FR and GSP-FR) were collected from two commercial-scale gasifiers (GE water-slurry slagging entrained flow gasifier and GSP slagging pulverized entrained flow gasifier) from the Ningdong Energy and Chemical Industry Base located in Yinchuan, Ningxia Hui Autonomous Region, China [39]. The Ningdong Energy and Chemical Industry Base is one of the most advanced industrial complexes in China developing clean coal technology. In the Ningdong Energy and Chemical Industry Base, Ningxia, China, 4.737 million tons of coal are consumed for coal gasification annually resulting in 1.046 million tons of residues [40]. The feed coals (ground to $75 \mu \mathrm{m}$ ), characterized by high volatile matter, are bituminous coals from the Jurassic Yan'an Formation. GE-C was from the Yangchangwan Coal Mine and GSP-C was from the Meihuajing Coal Mine. Gasification operation parameters are presented in Table 1.

Table 1. Gasification operation parameters and sample number.

\begin{tabular}{cccccccc}
\hline $\begin{array}{c}\text { Gasification } \\
\text { Technology }\end{array}$ & Feed Coal & $\begin{array}{c}\text { Gasification } \\
\text { Residues }\end{array}$ & $\begin{array}{c}\text { Feed Coal } \\
\text { Mine }\end{array}$ & $\begin{array}{c}\text { Status of } \\
\text { Feed Coal }\end{array}$ & $\begin{array}{c}\text { Gasification } \\
\text { Agent }\end{array}$ & $\begin{array}{c}\text { Temperature } \\
\left({ }^{\circ} \mathbf{C}\right)\end{array}$ & $\begin{array}{c}\text { Pressure } \\
(\mathbf{M P a})\end{array}$ \\
\hline $\mathrm{GE}^{1}$ & $\mathrm{GE}^{2} \mathrm{C}^{3}$ & $\begin{array}{c}\text { GE-CR } \\
\text { GE-CR-B } \\
\text { GE-FR }\end{array}$ & $\mathrm{YCW}^{6}$ & $\mathrm{CWS}^{8}$ & Oxygen & 1250 & 4.3 \\
\hline $\mathrm{GSP}^{2}$ & GSP-C & $\begin{array}{c}\text { GSP-CR } \\
\text { GSP-FR }\end{array}$ & $\mathrm{MHJ}^{7}$ & $\mathrm{PC}^{9}$ & $\begin{array}{c}\text { Oxygen }+ \\
\text { Steam }\end{array}$ & $1350-1450$ & $3.8-4.0$ \\
\hline
\end{tabular}

${ }^{1}$ Former Texaco gasifier; ${ }^{2}$ Gaskombimat Schwarze Pumpe gasifier; ${ }^{3}$ Coal $;{ }^{4}$ Coarse residue; ${ }^{5}$ Fine residue; ${ }^{6}$ Yangchangwan; ${ }^{7}$ Meihuajing; ${ }^{8}$ Coal-water slurry; ${ }^{9}$ Pulverized coal.

\subsection{Analytical Methods}

\subsubsection{Proximate, Ultimate, and Total Sulfur Analyses}

Proximate analysis was performed on the feed coals and gasification residues following ASTM standards D3173-11 [41], D3174-11 [42], and D3175-11 [43]. Total sulfur was determined according to the ASTM standard D3177-02 (Reapproved 2007) [44]. Ultimate analysis was determined following ASTM standard D5373-08 [45]. 


\subsubsection{SEM-EDX and XRD Analyses}

In order to evaluate more fully the mineralogical characteristics of the coal and coal gasification residues, the feed coals and the coarse residues were ground ( $<20$ mesh) following ASTM Standard D5671-95 (Reapproved 2011) [46], then mounted in resin and prepared as polished sections for electron microscopy study, but the particle size of the fine residues had already met the requirements of microscopic analysis without further grinding. A MERLIN scanning electron microscope (SEM) (Tsinghua University, Beijng, China) with associated energy-dispersive X-ray (EDX) element analyzer (Tsinghua University, Beijing, China) was used to study the minerals and determine elemental distribution in the samples, using an accelerating voltage of $15 \mathrm{kV}$. Before SEM analysis, the polished sections were carbon coated.

The feed coals and the gasification residues were ground to pass 200 mesh and analyzed using X-ray diffraction (XRD) (Analytical Laboratory of Beijing Research Institute of Uranium Geology, Beijing, China) to determine the mineral components. A D/max-2500/TTR powder diffractometer with a $\mathrm{Cu}-\mathrm{K} \alpha$ radiation was selected for $\mathrm{XRD}$ investigation, using an accelerating voltage and current of $40 \mathrm{kV}$ and $40 \mathrm{~mA}$, respectively. The XRD pattern used for the feed coals was recorded over a $2 \theta$ interval of $2.5-70^{\circ}$, with a step size of $0.02^{\circ}$, and the XRD pattern used for the residues was recorded over a $2 \theta$ interval of $5.0-70^{\circ}$, with a step size of $0.13^{\circ}$.

\subsubsection{Protocol of Sequential Chemical Extraction}

Mode of occurrences of seventeen environmentally-sensitive trace elements, including $\mathrm{Be}, \mathrm{V}, \mathrm{Cr}$, $\mathrm{Co}, \mathrm{Ni}, \mathrm{Cu}, \mathrm{Zn}, \mathrm{As}, \mathrm{Se}, \mathrm{Mo}, \mathrm{Cd}, \mathrm{Sb}, \mathrm{Ba}, \mathrm{Hg}, \mathrm{Tl}, \mathrm{Pb}$, and $\mathrm{U}$, were studied using a five-step sequential chemical extraction procedure. The coal and coarse residue samples were crushed and ground to pass a 200-mesh sieve, while the fine residue samples were fine enough to pass a 200-mesh sieve without being crushed. The sequential chemical extraction protocol used in this study is described below (Figure 1).

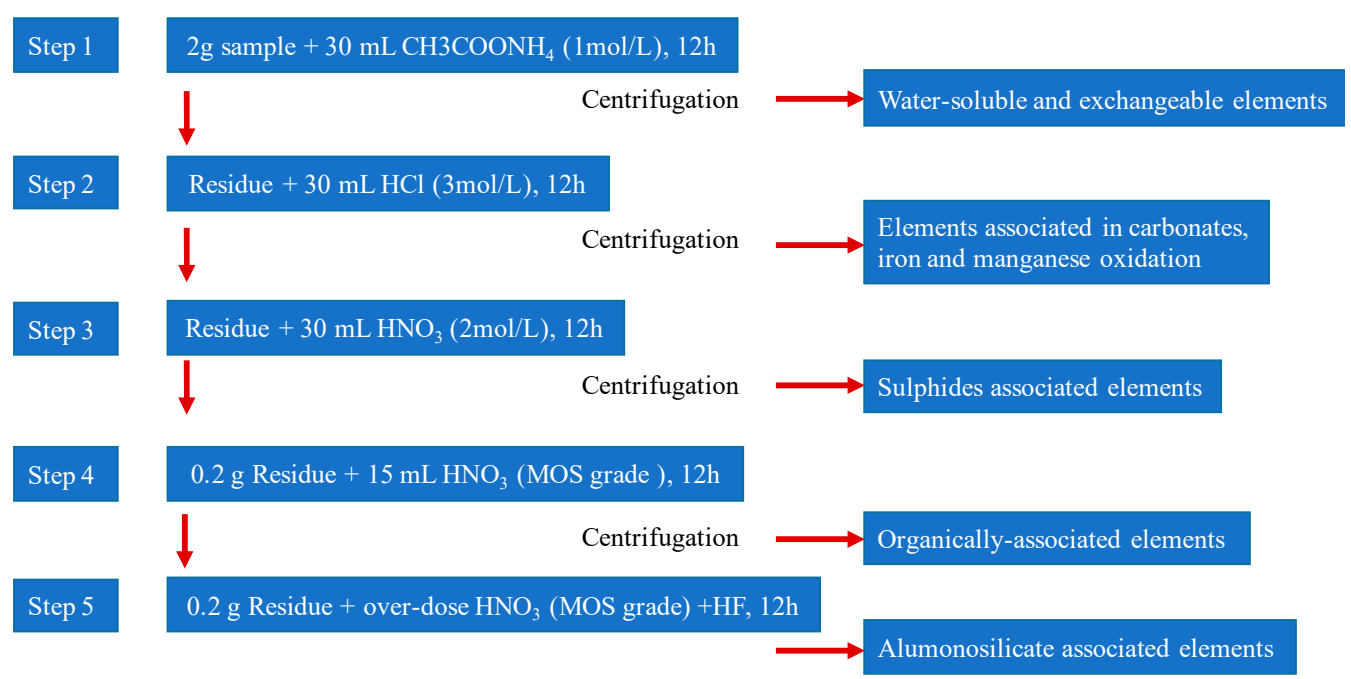

Figure 1. Diagram of the sequential chemical extraction method.

Stage 1: For elements that are water-soluble and exchangeable, approximately $2 \mathrm{~g}$ of the samples was shaken with $30 \mathrm{~mL}$ of $1 \mathrm{~mol} / \mathrm{L}$ ammonium acetate $(\mathrm{pH}=7)$ in a sealed centrifuge tube for a period of time up to $12 \mathrm{~h}$. The resulting solution was centrifuged at $4000 \mathrm{rpm}$ for $10 \mathrm{~min}$. The supernatant solution was extracted using a $0.45 \mu \mathrm{m}$ membrane filter for ICP-MS analysis.

Stage 2: For elements associated with carbonates and iron and manganese oxides, the solids remaining from Stage 1 were shaken with $30 \mathrm{~mL}$ of $3 \mathrm{~mol} / \mathrm{L} \mathrm{HCl}(10.42 \%)$ for up to $12 \mathrm{~h}$. The resulting 
solution was centrifuged at $4000 \mathrm{rpm}$ for $10 \mathrm{~min}$. The supernatant solution was extracted using a $0.45 \mu \mathrm{m}$ membrane filter for ICP-MS analysis.

Stage 3: For sulfides associated elements, the solids remaining from Stage 1 were shaken with $30 \mathrm{~mL}$ of $2 \mathrm{~mol} / \mathrm{L} \mathrm{HNO}_{3}(11.83 \%$ ) for up to $12 \mathrm{~h}$. the resulting solution were centrifuged at $4000 \mathrm{rpm}$ for $10 \mathrm{~min}$. The supernatant solution was extracted using a $0.45 \mu \mathrm{m}$ membrane filter for ICP-MS analysis.

Stage 4: For elements associated with the organic matter, $0.2 \mathrm{~g}$ of the solids remaining from Stage 3 were digested with $15 \mathrm{~mL}$ of concentrated $\mathrm{HNO}_{3}$ (about 73\%) using a microwave digestion system and sealed Teflon vessels. The resulting solution was centrifuged at $4000 \mathrm{rpm}$ for $10 \mathrm{~min}$. The supernatant solution was extracted using a $0.45 \mu \mathrm{m}$ membrane filter for ICP-MS analysis.

Stage 5: For elements in silicates, any remaining solid was digested using the microwave digestion system with over-dose concentrated $\mathrm{HNO}_{3}$ (about 73\%) and $\mathrm{HF}(40 \%)$. The final solution was transferred to a Teflon crucible for ICP-MS analysis.

\subsubsection{Trace Elements Concentration Analyses}

Concentrations of As and Se in the samples and in each extract solution were determined using atomic fluorescence spectrometry (AFS) (State Key Laboratory of Coal Resources and Safe Mining (CUMTB), Beijing, China). The content of $\mathrm{Hg}$ in the samples and in each extract solution was determined using a DMA-80 mercury analyzer (State Key Laboratory of Coal Resources and Safe Mining (CUMTB), Beijing, China), as outlined by Dai et al. [47]. Other trace elements Be, Cr, $\mathrm{Co}, \mathrm{Ni}, \mathrm{Cu}, \mathrm{Zn}, \mathrm{Mo}, \mathrm{Cd}, \mathrm{Sb}, \mathrm{Ba}, \mathrm{Tl}, \mathrm{Pb}$, and $\mathrm{U}$ in the samples, and in each of the solutions, were determined using inductively-coupled plasma mass spectrometry (ICP-MS), based on the methods for coal and coal-related materials outlined by Dai et al. [48]. After obtaining the concentrations of the trace elements the proportion of each mode of occurrence in the samples were calculated.

\section{Results and Discussion}

Proximate and ultimate analyses of the feed coal and residue samples are shown in Table 2. The feed coals used for gasification were low-ash and low-sulfur coals (GB/T 15224.1-94 [49] and GB/T 15224.2-1994 [50]).

Table 2. Proximate and ultimate analysis of feed coal and residue samples (wt \%).

\begin{tabular}{ccccccccccc}
\hline Samples & $\mathbf{M}_{\mathbf{a d}}$ & $\mathbf{A}_{\mathbf{d}}$ & $\mathbf{V}$ & $\mathbf{F C}_{\mathbf{d}}$ & $\mathbf{S}_{\mathbf{t} \mathbf{d}}$ & $\mathbf{C}_{\mathbf{d a f}}$ & $\mathbf{H}_{\mathbf{d a f}}$ & $\mathbf{N}_{\mathbf{d a f}}$ & $\mathbf{O}_{\mathbf{d a f}}{ }^{*}$ & $\mathbf{P}_{\mathbf{d a f}}$ \\
\hline GE-C & 5.34 & 10.1 & $32.44^{\mathrm{a}}$ & 60.73 & 0.73 & 78.93 & 4.47 & 0.82 & 14.96 & 0.01 \\
GE-CR-A & 5.78 & 72.17 & $4.01^{\mathrm{b}}$ & 23.82 & 0.55 & 95.87 & 0.29 & 0.68 & 1.15 & 0.06 \\
GE-CR-B & 5.91 & 49.84 & $6.21^{\mathrm{b}}$ & 43.96 & 0.71 & 94.06 & 0.38 & 0.56 & 3.61 & 0.03 \\
GE-FR & 9.88 & 69.34 & $6.77^{\mathrm{b}}$ & 23.89 & 1.08 & 92.14 & 0.36 & 0.59 & 3.39 & 0.12 \\
GSP-C & 6.9 & 16.24 & $35.88^{\mathrm{a}}$ & 53.71 & 1.22 & 77.58 & 4.74 & 1.01 & 15.2 & 0.02 \\
GSP-CR & 0.07 & 96.97 & $1.06^{\mathrm{b}}$ & 1.97 & 0.35 & 75.91 & 6.6 & 1.65 & 4.29 & 3.77 \\
GSP-FR & 2.26 & 67.12 & $2.72^{\mathrm{b}}$ & 30.16 & 0.68 & 93.22 & 0.91 & 0.43 & 3.41 & 0.34 \\
\hline
\end{tabular}

M: moisture; A: ash; V: volatile matter; FC: fixed carbon; St: total sulfur; C: carbon; H: hydrogen; N: nitrogen; O: oxygen; P: phosphorus. ad: air-dried basis; d: dry basis; daf: dry and ash-free basis; ${ }^{a} \mathrm{~V}_{\mathrm{daf}} ;{ }^{\mathrm{b}} \mathrm{V}_{\mathrm{d}}$; ${ }^{*}$ by difference.

\subsection{Mineralogical Characteristics of Samples}

Minerals in the feed coals, determined by XRD and SEM-EDX, include clay minerals, quartz, pyrite, and calcite (Figures 2 and 3A-D). In addition, siderite was identified in the GE-C (Figure 2A) and feldspar (potassium feldspar and plagioclase) was determined in the GSP-C sample (Figure 2B) by XRD. Inorganic matter in the gasification residues determined by XRD and SEM-EDX include quartz, calcite, and glass (Figures 2 and 3E-I). In addition, gehlenite and melilite were identified in the GE residues (Figure 2B) by XRD. The XRD analyses of the residues are shown in Table 3.

The temperatures in the slagging entrained-flow gasifiers were about $1250-1450{ }^{\circ} \mathrm{C}$ (Table 1 ). Inorganic matter in the gasification residues primarily consist of minerals whose ash fusion temperature (AFT) is higher than the temperature in the gasifiers [13]. Quartz is the main relic mineral in the 
gasification residues due to its high AFT. However, quartz could also take part in the formation of glass (amorphous silicates) reacting with various components (e.g., alkaline oxides) or minerals (e.g. pyrite and siderite). Kim [51] indicated that crystalline structures would be developed downstream if the liquid phases cool slowly. Therefore, the large amounts of calcite determined in the residues probably formed from recrystallization during residue cooling [52-54]. Reifenstein et al. [55] indicated that, in high-temperature environments, gehlenite and melilite were formed from the reaction of $\mathrm{CaO}$ released from calcite decomposition and amorphous silicoaluminate oxides generated from metakaolin.

Table 3. Inorganic matter in the feed coal and gasification residues (\%).

\begin{tabular}{cccccccc}
\hline \multirow{2}{*}{ Inorganic Matter } & \multicolumn{3}{c}{ Feed Coal } & \multicolumn{5}{c}{ Gasification Residues } \\
\cline { 2 - 8 } & GE-C & GSP-C & GE-CR-A & GE-CR-B & GE-FR & GSP-CR & GSP-FR \\
\hline Quartz & 27.9 & 34.9 & 18.7 & 13.3 & 75.9 & 55.2 & 35.2 \\
Potassium feldspar & - & 3.2 & - & - & - & - & - \\
Plagioclase & - & 1.6 & - & - & - & - & - \\
Calcite & 6.4 & 1.4 & 12.6 & 40.4 & 9.8 & - & 45.1 \\
Siderite & 7 & - & - & - & - & - & - \\
Pyrite & 5.4 & 1.6 & - & - & - & - & - \\
Clay minerals & 53.3 & 57.4 & - & - & - & - & - \\
Gehlenite & - & - & 58.8 & 5.3 & 5.4 & - & - \\
Melilite & - & - & - & - & 6 & - & - \\
Glass & - & - & 9.9 & 41 & 2.9 & 44.8 & 19.7 \\
\hline
\end{tabular}
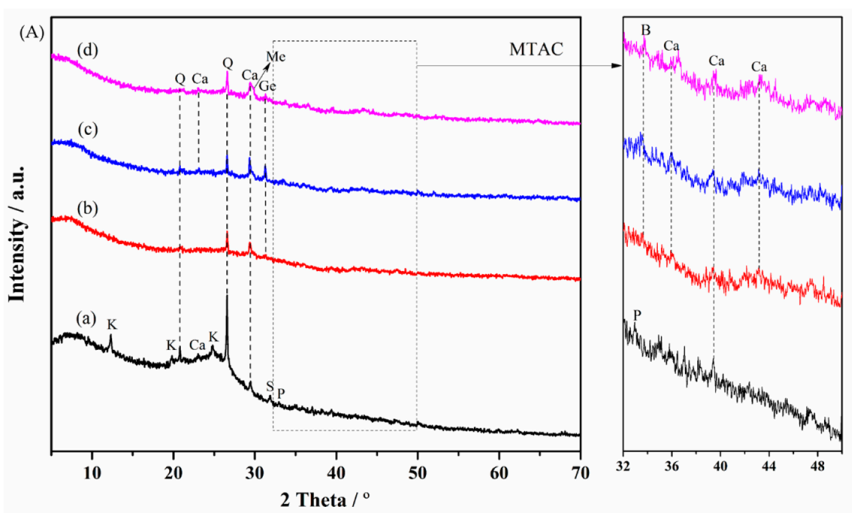

\section{(a) GE-C}

(b) GE-CR-A

(c) GE-CR-B

(d) GE-FR

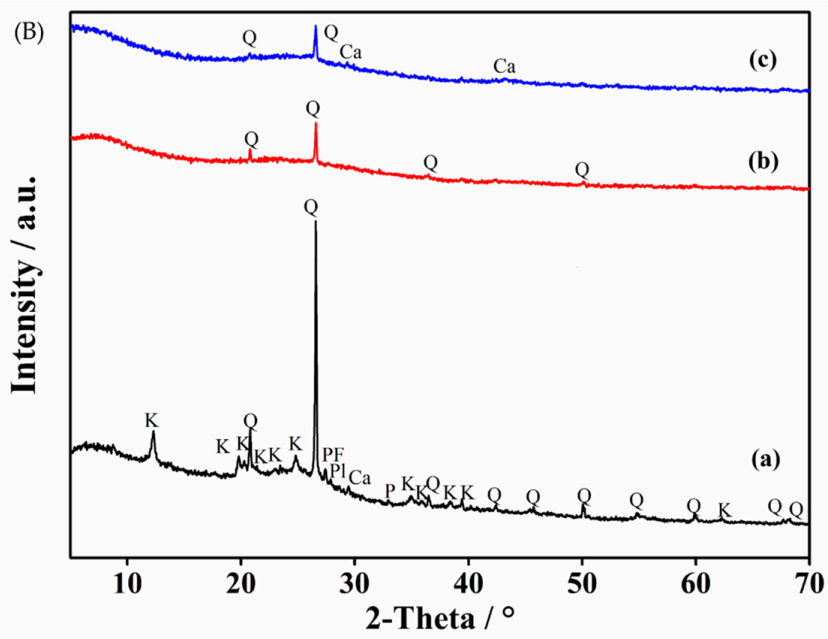

(a) GSP-C

(b) GSP-CR

(c) GSP-FR

Figure 2. XRD diffractograms of minerals in the feed coal and gasification residues: (A) samples from the coal to methanol plant (GE); and (B) samples from the coal to olefin plant (GSP). K-kaolinite; Q-quartz; Ca-calcite; Ge-gehlenite; S-siderite; P-pyrite; Me-melilite; PF-potassium feldspar; and Pl-plagioclase. 

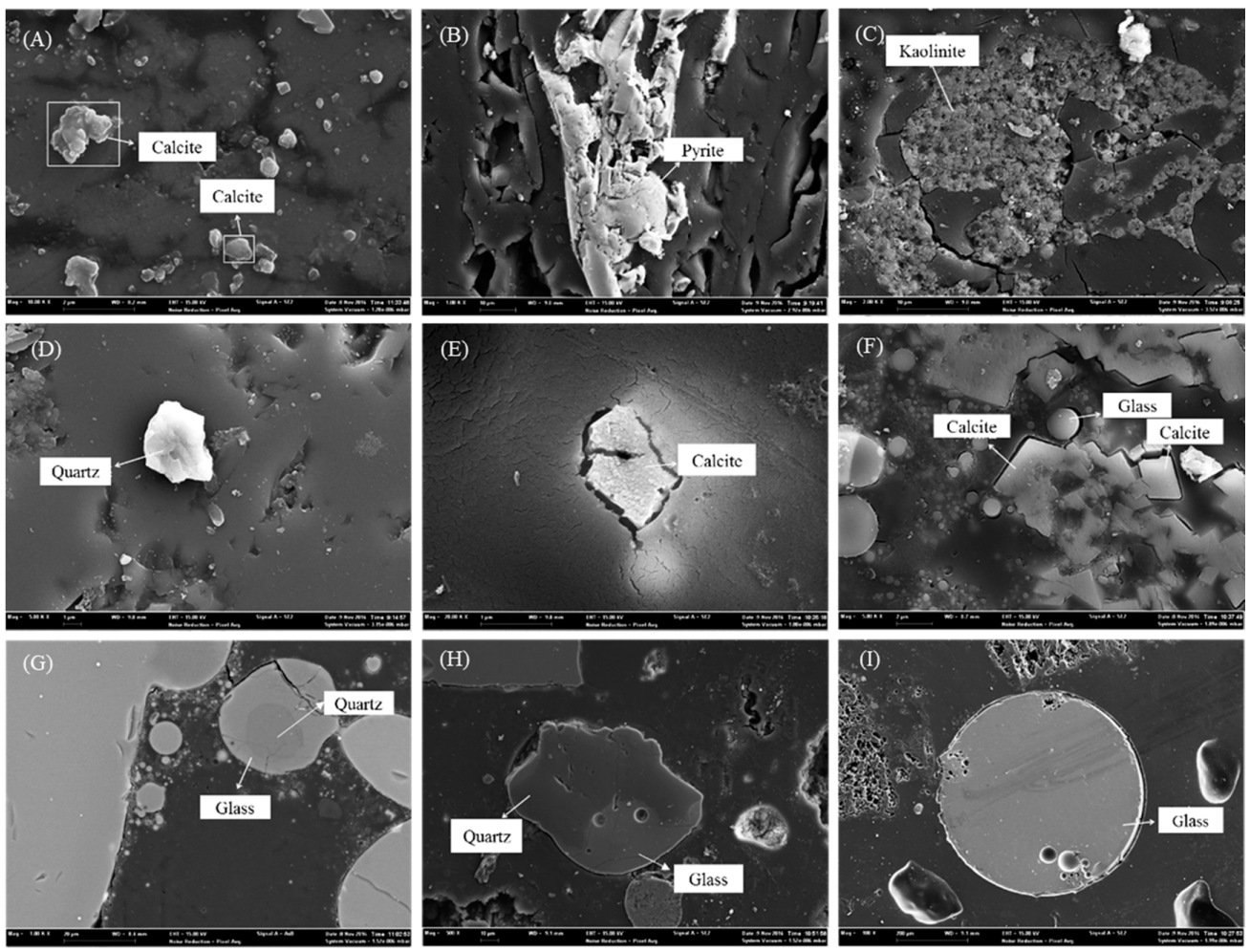

Figure 3. Minerals and glass in the gasification residues: (A) calcite in GE-C; (B) pyrite in GSP-C; (C) kaolinite in GSP-C; (D) quartz in GSP-C; (E) calcite in GSP-CR; (F) calcite and glass in GSP-FR; (G) quartz and glass in GSP-CR; (H) quartz and glass in GE-FR; and (I) glass in GE-CR (SEM, (A-F) secondary electron images; and (G-I) back-scatting images).

\subsection{Concentrations of the Selected Trace Elements}

The concentrations of the selected trace elements in the feed coals and gasification residues are shown in Table 4. The concentrations of most trace elements in the feed coals were lower than the average concentrations in Chinese coals as reported by Dai et al. [56]. The concentrations of Ba in GE-C and $\mathrm{Cr}, \mathrm{Pb}, \mathrm{Cu}, \mathrm{Zn}, \mathrm{Ba}$, and $\mathrm{Tl}$ in GSP-C were higher than the corresponding average values in Chinese coals (Figure 4). In the GSP-C sample, the concentration of $\mathrm{Cu}$ was 18 times higher than that in the Chinse coals. However, concentrations of $\mathrm{Cu}$ in the residues were not enriched compared with the average value of trace elements in hard coal ash [57].

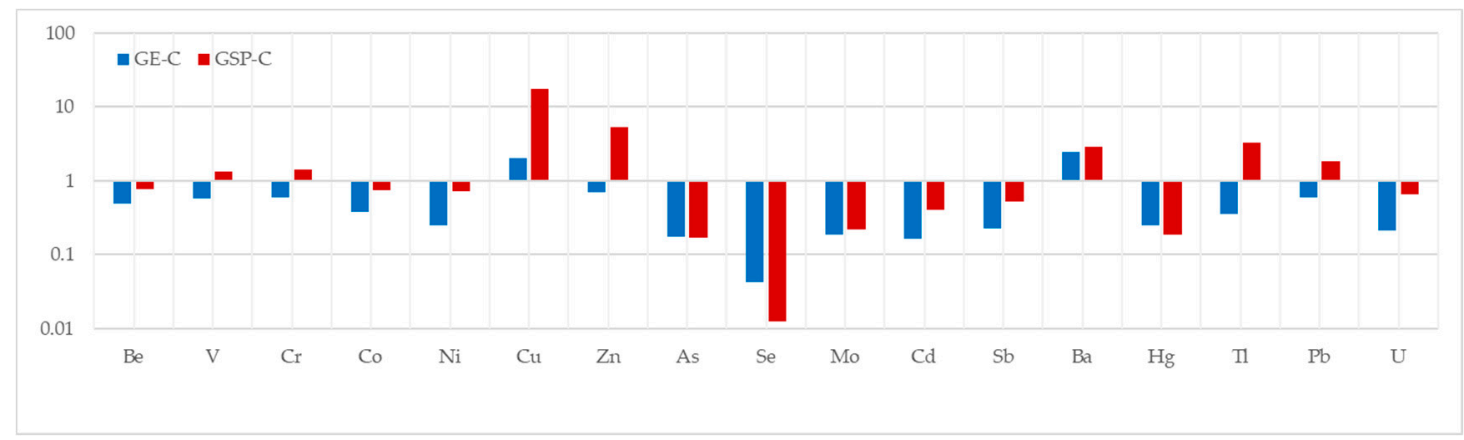

Figure 4. Concentration coefficients (CC) for the feed coals (CC, the ratio of investigated samples vs. the average concentrations in Chinese coal). 
After the coal gasification processes, trace elements in the feed coals migrated into the coarse residues and fine residues unevenly. In the samples investigated, concentrations of most trace elements in the fine residues were higher than that in the coarse residues (Table 4). Previous investigations [4,6,9-11] indicated that some volatile trace elements tended to be enriched in smaller particles because the finer particles have a greater surface area. However, concentrations of Be, $\mathrm{V}$, and $\mathrm{Ba}$ in the GSP-CR were higher than that in the GSP-FR (Table 4). Clarke [6] suggested that Ba, V, and Be have low volatility, preferentially concentrating in the coarse residues during combustion and gasification processes. Compared with the average value of trace elements in world hard coal ash [58], concentrations of $\mathrm{Cd}, \mathrm{Pb}, \mathrm{Zn}, \mathrm{Sb}, \mathrm{Ba}$, and $\mathrm{Tl}$ in GE-FR and $\mathrm{Ba}$ and $\mathrm{Tl}$ in GSP-FR were considerably higher. Thus, the gasification residues could be considered as a raw material for extracting some critical elements [58,59].

Table 4. Concentrations of trace elements in the feed coal and different residue samples $(\mu \mathrm{g} / \mathrm{g})$.

\begin{tabular}{|c|c|c|c|c|c|c|c|c|c|}
\hline \multirow{2}{*}{ TEs } & \multicolumn{2}{|c|}{ Feed Coal } & \multicolumn{5}{|c|}{ Gasification Residues } & \multirow{2}{*}{ Coal [56] } & \multirow{2}{*}{ Hard Coal Ash [57] } \\
\hline & GE-C & GSP-C & GE-CR-A & GE-CR-B & GE-FR & GSP-CR & GSP-FR & & \\
\hline $\mathrm{Be}$ & 1.04 & 1.63 & 2.61 & 3.47 & 5.09 & 7.07 & 4.32 & 2.11 & $12 \pm 1$ \\
\hline $\mathrm{V}$ & 20.1 & 46 & 79.4 & 80.4 & 127 & 124 & 110 & 35.1 & $170 \pm 10$ \\
\hline $\mathrm{Cr}$ & 9.1 & 21.7 & 81.1 & 67.5 & 83.4 & 72.4 & 58.6 & 15.4 & $120 \pm 5$ \\
\hline Co & 2.66 & 5.23 & 21.5 & 19 & 33.8 & 24.5 & 26.7 & 7.08 & $37 \pm 2$ \\
\hline $\mathrm{Ni}$ & 3.36 & 9.82 & 42.7 & 34.1 & 57.7 & 28.1 & 36.9 & 13.7 & $100 \pm 5$ \\
\hline $\mathrm{Cu}$ & 35.5 & 310 & 44.7 & 47.4 & 74.3 & 38.7 & 82.6 & 17.5 & $110 \pm 5$ \\
\hline $\mathrm{Zn}$ & 29 & 221 & 26 & 25.4 & 222 & 13.5 & 111 & 41.4 & $170 \pm 10$ \\
\hline As & 0.655 & 0.633 & 2.47 & 4.7 & 31.4 & 1.64 & 5.62 & 3.79 & $46 \pm 5$ \\
\hline Se & 0.105 & 0.031 & 0.32 & 0.508 & 6.86 & 0.085 & 0.76 & 2.47 & $10.0 \pm 0.7$ \\
\hline Mo & 0.572 & 0.674 & 0.996 & 1.55 & 3.32 & 1.34 & 2.63 & 3.08 & $14 \pm 1$ \\
\hline $\mathrm{Cd}$ & 0.041 & 0.101 & 0.128 & 0.07 & 1.65 & 0.212 & 0.36 & 0.25 & $1.2 \pm 0.3$ \\
\hline $\mathrm{Sb}$ & 0.189 & 0.443 & 0.37 & 0.449 & 7.56 & 0.184 & 1.33 & 0.84 & $7.5 \pm 0.6$ \\
\hline $\mathrm{Ba}$ & 388 & 457 & 1141 & 1140 & 1456 & 1902 & 984 & 159 & $980 \pm 60$ \\
\hline $\mathrm{Hg}$ & 0.04 & 0.03 & 0.002 & 0.006 & 0.001 & 0.002 & 0.006 & 0.163 & $0.87 \pm 0.07$ \\
\hline $\mathrm{Tl}$ & 0.169 & 1.52 & 0.532 & 0.655 & 7.22 & 0.729 & 5.77 & 0.47 & $4.6 \pm 0.4$ \\
\hline $\mathrm{Pb}$ & 8.94 & 27.6 & 8.95 & 7.31 & 206 & 3.52 & 48.6 & 15.1 & $55 \pm 6$ \\
\hline $\mathrm{U}$ & 0.513 & 1.58 & 3.73 & 3.9 & 7.37 & 5.59 & 5.56 & 2.43 & $15 \pm 1$ \\
\hline
\end{tabular}

TEs: trace elements. Mercury concentration was determined by a DMA-80 mercury analyzer. Arsenic and Se concentrations were determined using atomic fluorescence spectrometry (AFS) and other elements were determined by ICP-MS.

\subsection{Distribution of the Selected Trace Elements Based on RE (Relative Enrichment)}

Distribution of trace elements in the gasifiers or boilers depends on their volatility, as well as their concentrations and modes of occurrence in the coal [60]. Clarke [6] summarized the fate of trace elements during coal combustion and gasification, indicating that trace element partitioning behavior during coal gasification is similar to their distribution during coal combustion [61]. Meij [62] employed the concept of relative enrichment (RE) to classify trace elements in thermal systems and the formula of RE was also adopted by Duchesne et al. [63]. Duan [64] considered that ash yield of the residues should be taken into account in the formula when calculating the RE of trace elements in residues. Hower et al. [12] updated the classification of trace elements in bottom ash, fly ash, and flue gas after Clarke [6] and Meij [62], indicating that the actual performance of trace elements may vary. RE is defined as follows:

$$
\mathrm{RE}=\frac{\mathrm{C}_{\text {residue }}}{\mathrm{C}_{\text {coal }}} \times \frac{\mathrm{A}_{\mathrm{ad}_{\text {coal }}}}{\mathrm{A}_{\mathrm{ad}_{\text {residue }}}}
$$

where $C_{\text {residue }}$ is the trace element concentration in the residues, $\mu \mathrm{g} / \mathrm{g} ; C_{\text {coal }}$ is the trace element concentration in the feed coal, $\mu \mathrm{g} / \mathrm{g} ; \mathrm{A}_{\mathrm{ad}_{\text {residue }}}$ is the ash yield in the residue, $\%$; and $\mathrm{A}_{\mathrm{ad}_{\text {coal }}}$ is the ash yield in the feed coal, \%.

According to this formula and the concentrations of trace elements in the gasification residues, the REs of all 17 elements were calculated. REs for GE-CR-A and GE-FR and REs for GSP-CR and GSP-FR were used to make a scatter plot (Figure 5). If the $R E=1$, the trace element neither concentrates 
nor depletes in the residues; if the RE > 1, the trace element tends to enrich in the residues; if the RE $<1$, the trace element tends to deplete in the residues. The scatter plot (Figure 5), was divided into four quadrants by lines of $\mathrm{RE}=1$ for coarse and fine residues. Trace elements plotted in quadrant $\mathrm{A}$ were depleted in both fine and coarse residues, these included $\mathrm{Hg}$, $\mathrm{Ba}, \mathrm{Be}, \mathrm{Mo}, \mathrm{V}$, and $\mathrm{Cu}$ in the GE and GSP gasification processes. In addition, $\mathrm{Cr}, \mathrm{Cd}, \mathrm{U}, \mathrm{Ni}, \mathrm{Pb}, \mathrm{Sb}, \mathrm{Zn}$, and $\mathrm{Tl}$ in the $\mathrm{GE}$ gasification process was also plotted in quadrant A. Trace elements plotted in quadrant B were depleted in the fine residues, but enriched in the coarse residues, but no elements were plotted in this quadrant. Trace elements plotted in quadrant $C$ were enriched in both fine and coarse residues, included $\mathrm{Cr}, \mathrm{Co}, \mathrm{Ni}$, and U during the GSP gasification process. Trace elements plotted in quadrant D were depleted in the coarse residues, but enriched in the fine residues, including As and Se in the GE and GSP gasification processes. In addition, $\mathrm{Co}$ from the $\mathrm{GE}$ gasification process, and $\mathrm{Zn}, \mathrm{Pb}, \mathrm{Sb}, \mathrm{Cd}$, and $\mathrm{Tl}$ from the GSP gasification process, were plotted in quadrant $\mathrm{D}$. In this study, $\mathrm{Hg}, \mathrm{Ba}, \mathrm{Be}, \mathrm{Mo}, \mathrm{V}, \mathrm{Cu}, \mathrm{As}$, and Se showed the same partitioning behavior during the GE and GSP gasification processes. Although behaviors of trace elements in gasifiers are similar to their behavior in combustors, volatile species may differ due to the reducing environment in the gasifiers $[12,65]$.

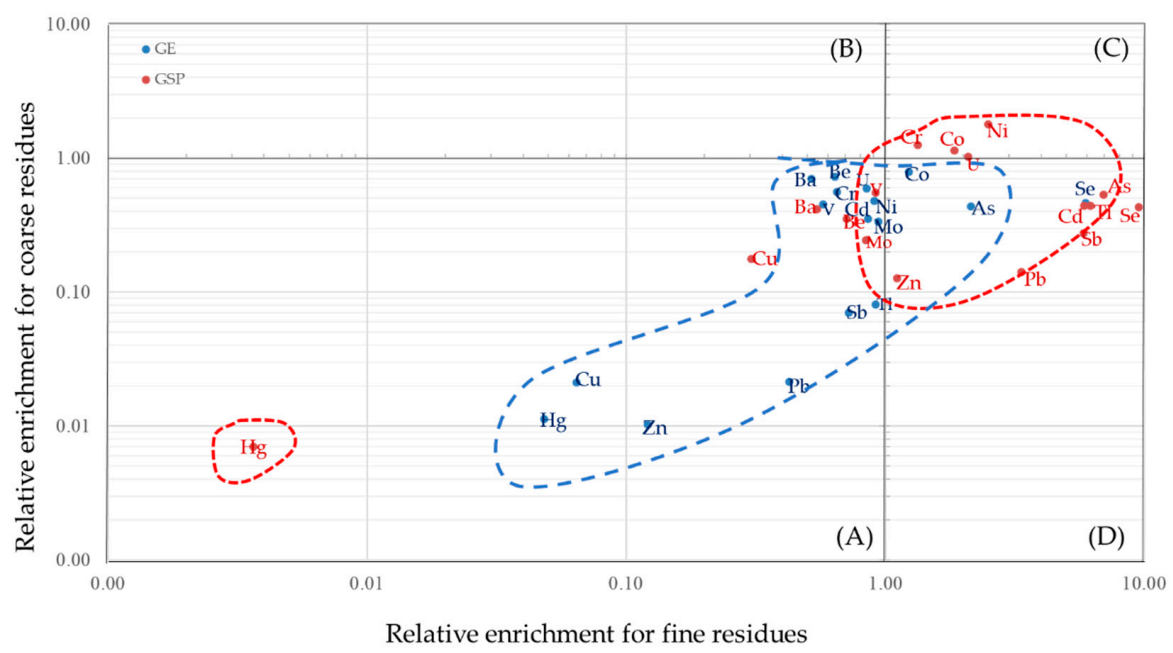

Figure 5. Enrichment behavior of elements in gasification residue samples, (A) trace elements depleted in both coarse and fine residues; (B) trace elements depleted in the fine residues, but enriched in the coarse residue; (C) trace elements enriched in both fine and coarse residues; (D) trace elements depleted in the coarse residues, but enriched in the fine residues.

\subsubsection{Volatile Trace Elements}

Mercury (Hg)

Mercury is of particular concern due to its negative impacts to human health and the environment [66,67]. Finkelman [68] showed that mercury was primarily associated with pyrite and proposed a relatively high confidence level of 6 out of 10. Swaine [69] states that Hg is probably associated with pyrite and sometimes sphalerite. Mercury, assumed to be organically bound, may be associated with finely dispersed pyrite, which is protected by the coal matrix. A number of studies [36,70-73] showed the mode of occurrence of $\mathrm{Hg}$ is predominantly associated with pyrite. Finkelman [30] emphasizes that around $90 \%$ of the $\mathrm{Hg}$ is associated with sulfides likely with pyrite which is the predominant sulfide in most bituminous coals and at least $75 \%$ was associated with sulfide minerals in low rank coals. Other forms of $\mathrm{Hg}$ in coal that have been reported include organically-bound, elemental, and selenide minerals [74].

The data of sequential chemical extraction for $\mathrm{Hg}$ in this study is shown in Figure 6. About $60 \%$ of the Hg in GE-C (Figure 6A) and GSP-C (Figure 6B) was associated with sulfides (likely pyrite). 
The proportion of $\mathrm{Hg}$ associated with silicates (likely kaolinite) was about $30 \%$. About $10 \%$ of the $\mathrm{Hg}$ in the feed coals was determined to be in the carbonates (likely calcite), iron and manganese oxides.

In the GE-CR-A and GSP-CR samples, $\mathrm{Hg}$ was only associated with silicates, but in the smaller particle GE-CR-B, Hg was also associated with sulfides (Figure 6A,B). Comparing the concentrations of $\mathrm{Hg}$ associated with the silicates and sulfides in the coarse residues with that in the feed coals, the concentration of $\mathrm{Hg}$ in the coarse residues was slightly lower (Figure 6C,D). This shows clearly that $\mathrm{Hg}$ associated with sulfides and carbonates and iron and manganese oxides was released with the decomposition of pyrite and calcite during coal gasification while $\mathrm{Hg}$ associated with the silicates was relatively difficult to be released. According to the composition of the gasification coarse residue identified by XRD and SEM-EDX (Table 3), the Al-Si glass and gehlenite were the main inorganic constituents, which could be the hosts of $\mathrm{Hg}$.

In the fine residues, three modes of occurrences of $\mathrm{Hg}$ was determined to be similar to that in the feed coals but the proportions of each mode of occurrences was different (Figure 6A,B). In the GE-FR sample, the concentration of $\mathrm{Hg}$ associated with the silicates increased compared with that in the GE-C (Figure 6C), this may be because the molten silicates could capture the vapor phase $\mathrm{Hg}$. Mercury associated with the sulfides in the fine residues may be from the unreacted coal particles which retain a small content of pyrite due to the short reactor residence time of the fine residues. In the GSP-FR sample, the proportion of $\mathrm{Hg}$ associated with the carbonates and iron and manganese oxides had increased (Figure 6B). During the process of liquid slag cooling a large amount of calcite could be recrystallized along with the silicate slag, so the $\mathrm{Hg}$ captured by the liquid slags was associated with the carbonates and iron and manganese oxides in the fine residues.

According to previous investigations $[6,8,9,11,12], \mathrm{Hg}$ is the most volatile trace element in thermal systems, escaping with the flus gas. In our study $\mathrm{Hg}$ was depleted in the gasification residues (Figure 5). Though the vapor phase $\mathrm{Hg}$ can be cooled and condense on particle surfaces, however, the concentrations of $\mathrm{Hg}$ in the fine residues were still low. The $\mathrm{Hg}$ retained in the residues largely depends on the presence of unburned carbon [12].
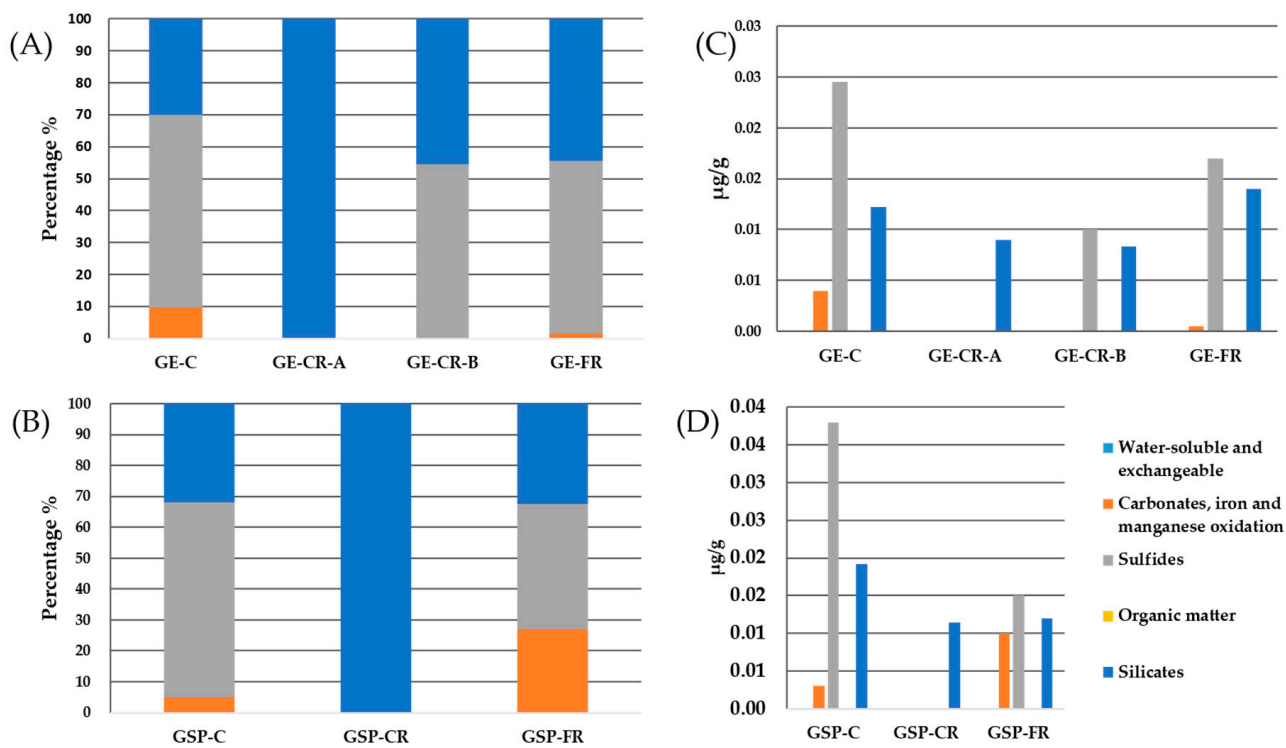

Figure 6. Sequential chemical leaching results for mercury:(A,B) percentage leached; and (C,D) the concentration in leachates.

Molybdenum (Mo)

Swaine [69] indicates that the mode of occurrence of Mo in coal varies from mostly inorganic to mostly organic. Finkelman [37] proposes that most of the molybdenum in coal may initially be associated with the silicates (clays) and organics. Sulfide-associated molybdenum will increase with 
up-ranking and epigenetic mineralization. From the results of sequential chemical extraction in this study (Figure 7A,B), about 40\% and 70\% Mo was in organic association in the GE-C and GSP-C samples, respectively. The proportion of Mo associated with the silicates (likely kaolinite) was about 30\% each in GE-C and GSP-C. In GE-C, about 20\% of the Mo was determined to be in the sulfides (likely pyrite). Studies by Dai et al. [75,76] and Liu et al. [34] showed that Mo in high-Mo coals is mainly associated clay minerals and organic matter.

In the GE gasification residues Mo was associated with the carbonates (likely calcite), iron and manganese oxides (Figure 7A). During the process of liquid slag cooling, a large amount of calcite could be recrystallized, so the Mo captured by the liquid slags was associated with the carbonates and with iron and manganese oxides in the fine residues. The percentage and concentration of Mo associated with the sulfides in the gasification residues were significantly higher than that in the feed coals (Figure 7A-D). The proportion of Mo associated with sulfides was around 40-60\% in the GE residues (Figure 7A). In the GSP residues, five modes of occurrence of Mo were determined, but the proportion of each mode of occurrence changed from the modes of occurrence of Mo in the feed coal (Figure 7B). Molybdenum associated with sulfides in the GSP-CR was around 80\%. The sulfides minerals should decompose completely considering the high peak temperature in the gasifiers. However, the environment in the gasifiers was complex with the temperature varying from $100{ }^{\circ} \mathrm{C}$ (dry zone in the gasifiers) to $1300{ }^{\circ} \mathrm{C}$ (combustion zone). Therefore, sulfides minerals could exist in the residues due to the short residence times and the uneven temperature in the gasifiers. According to the transformation of pyrite during coal gasification, pyrrhotite is one of the products transformed from the pyrite, so Mo determined in the sulfides could be associated with the pyrrhotite present in low concentrations [19]. The concentrations of Mo in the residues were higher than that in the feed coals (Table 4). Mo released in the vapor phase could be combined with sulfides, again forming molybdenum sulfide.
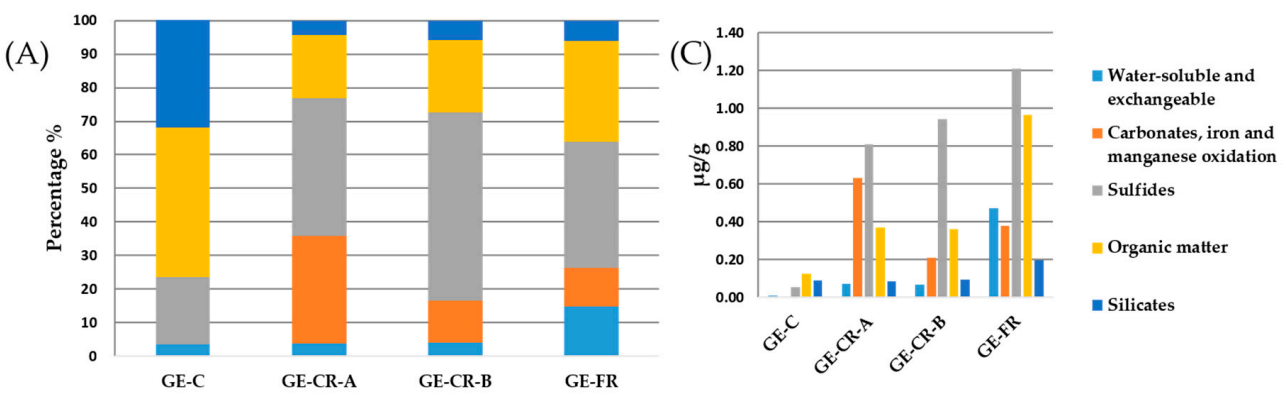

(B)

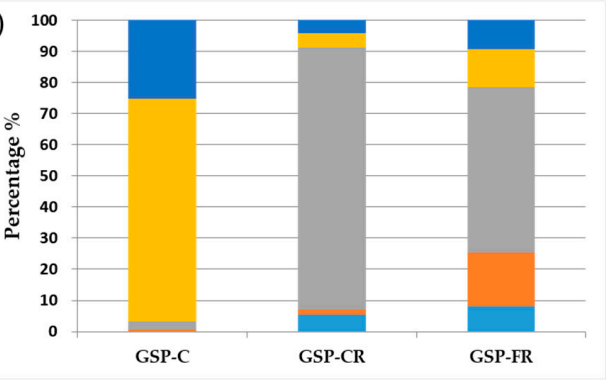

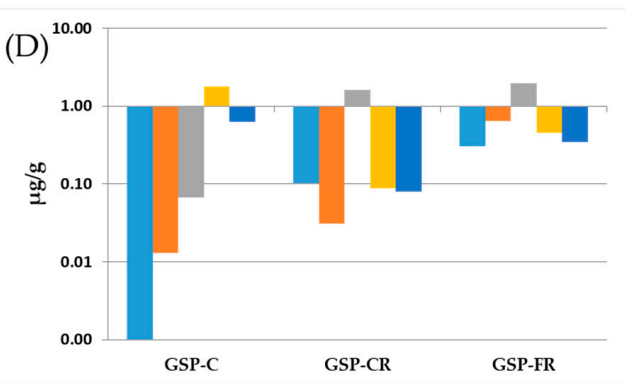

Figure 7. Sequential chemical leaching results for molybdenum: $(\mathbf{A}, \mathbf{B})$ percentage leached; and $(\mathbf{C}, \mathbf{D})$ the concentration in leachates.

According to the classification proposed by Hower et al. [12], Mo could not only escape with the flue gas, but could be trapped with fly ash in the combustion system. In our study, Mo was a volatile trace element according to its behavior during GE and GSP gasification (Figure 5). The reducing environment in the gasifier could enhance the volatility of Mo [11,61]. After gasification, Mo was mainly associated with the sulfides in the residues. 
Barium (Ba)

The mode of occurrence of Ba in coal may be mostly inorganic. Kortenski [77] reports that Ba may be associated with the organic matter in coals. $\mathrm{Xu}$ et al. [8] reviewed trace element emissions in a coal combustion process and summarized the modes of occurrence of trace elements, indicating that some of the $\mathrm{Ba}$ in coal is associated with clays and feldspars and some of the Ba could probably be present in sulfates. Spears [36] states that Ba is associated with clay minerals. The data of sequential chemical extraction for Ba in this study was shown in Figure 8. In the GE-C, around 70\% of the Ba was associated with the carbonates, iron and manganese oxides, with $15 \%$ in water-soluble forms and $10 \%$ associated with the silicates (Figure 8A). In the GSP-C, more than $50 \%$ of the Ba was associated with the silicates (clays), with $20 \%$ associated with the carbonates and iron and manganese oxides (Figure $8 \mathrm{~B}$ ). The sequential chemical extraction data for Ba was very close to the results from Finkelman [37].

After coal gasification, five modes of occurrences of $\mathrm{Ba}$ was determined in the gasification residues, the proportions and concentrations of modes of occurrence changed from that in the feed coal. In the coarse residues, about $90 \%$ of the Ba was associated with the carbonates and iron and manganese oxides, which indicates that Ba released from the silicates or carbonates could be captured by liquid slags and combined with the carbonates when the slag cools. In the fine residues $40-50 \%$ of the Ba was present in the carbonates, iron and manganese oxides. In the GE-FR, $30 \%$ of the Ba was associated with the sulfides. In the GSP-FR, about $40 \%$ of the Ba was still associated with the silicates. According to the proportion and concentration of Ba associated with the silicates in the GSP-C GSP-CR and GSP-FR samples, Ba in the silicates could be released upon heating, but then is combined by the carbonates in the residues. However, some Ba could still be fixed by silicates in the residues, especially in the fine residue (GSP-FR).
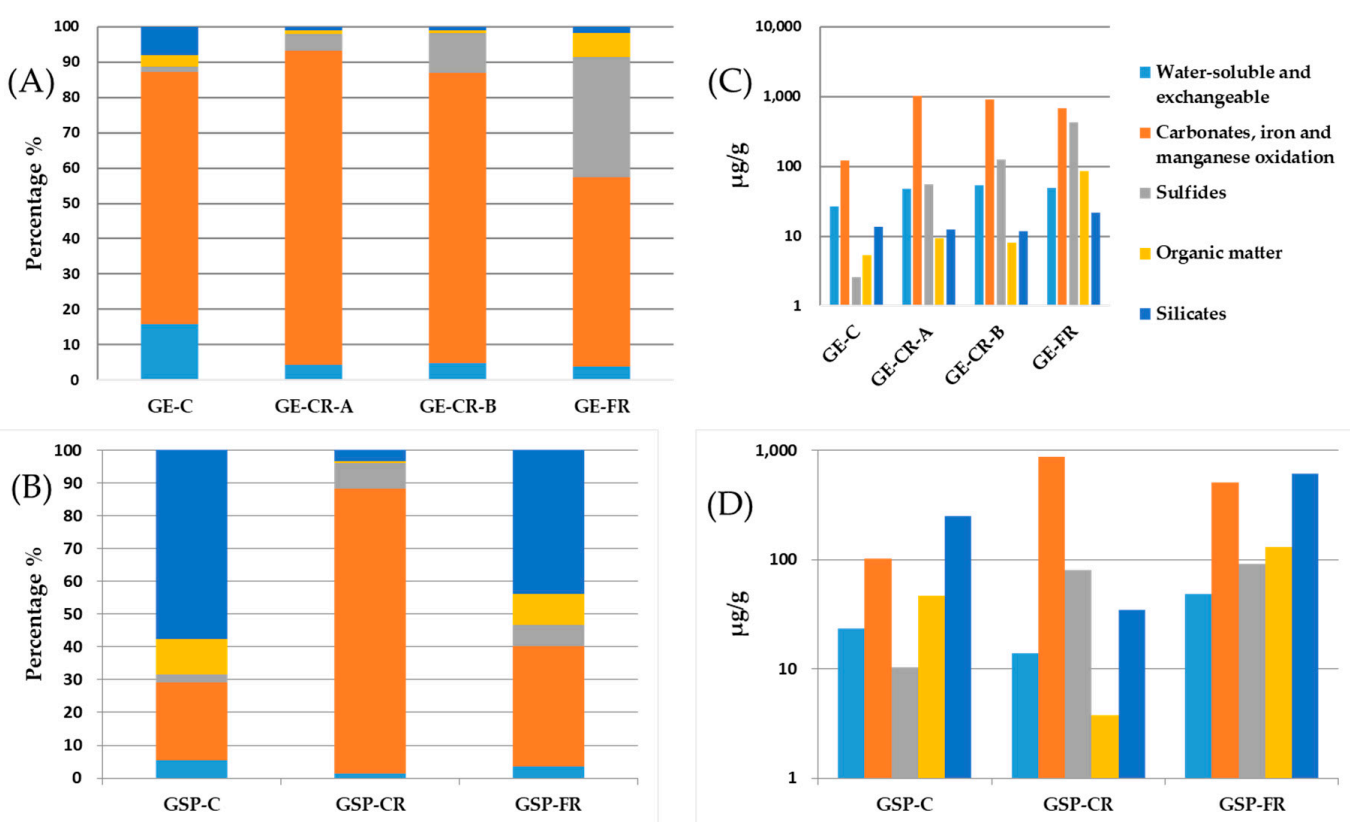

Figure 8. Sequential chemical leaching results for barium: $(\mathbf{A}, \mathbf{B})$ percentage leached; and $(\mathbf{C}, \mathbf{D})$ the concentration in leachates.

According to the classification proposed by Hower et al. [12], Ba could also be trapped with the fly ash and bottom ash in the combustion system as a less volatile element. In our study, Ba was a volatile trace element according to its behavior during GE and GSP gasification (Figure 5). The reducing environment in the gasifier could enhance the volatility of Ba [11,61]. After gasification, Ba was mainly associated with the carbonates and iron and manganese oxides in the residues. 


\section{Beryllium (Be)}

There is abundant evidence in the literature indicating that the mode of occurrence of Be in coal is mostly organic. Swaine [69] states that Be is mainly associated with the organic matter, but with some present in clays. Finkelman [68] confirms this and proposes the confidence level of Be associated with organic matter is 4 out of 10 . The modest level of confidence was attributed to the difficulty in determining the mode of the occurrence of Be due to its low concentration in coals and its low atomic weight [37]. According to the investigation from Finkelman [68] and Querol et al. [32], abundant evidence indicates an organic affinity for Be. However, Riley et al. [19] indicates that some Be in the Australian coals is associated with calcite. A recent study by Dai et al. [78] showed that Be is associated with sulfate minerals in high-Be coals from Lincang deposit, Yunnan, China. The data from sequential chemical extraction for Be in this study is shown in Figure 9. In GE-C, about $60 \%$ of the Be was associated with the carbonates and iron and manganese oxides, with $20 \%$ of the Be having an organic affinity (Figure 9A). In the GSP-C, more than $60 \%$ of the Be was silicate-bound, with $15 \%$ associated with the carbonates and iron and manganese oxides, and 15\% organically associated (Figure 9B).

After coal gasification, the proportion of Be in the carbonates and iron and manganese oxides in the coarse residues was more than $90 \%$ with only a minor amount associated with the organics (Figure 9A,B). This may be explained by Be being released from the organic matter, silicates, or carbonates, and iron and manganese oxides, and then captured by liquid slags combining with the carbonates when the slag cools. The transformation mechanism of Be from feed coal to the coarse residues during the coal gasification processes was similar to that of Ba. In the GE-FR and the GSP-FR samples about $80 \%$ and $60 \%$, respectively, of the Be was present in the carbonates and iron and manganese oxides, (Figure 9A,B). In the GSP-FR, more than $20 \%$ of the Be was still associated with the silicates. According to the proportion and concentration of Be associated with the silicates in the GSP-C GSP-CR and GSP-FR, Be in the silicates could be released upon heating, but then is combined with the carbonates in the residues. However, some Be could still be fixed by silicates in the residues, especially the fine residue (GSP-FR).
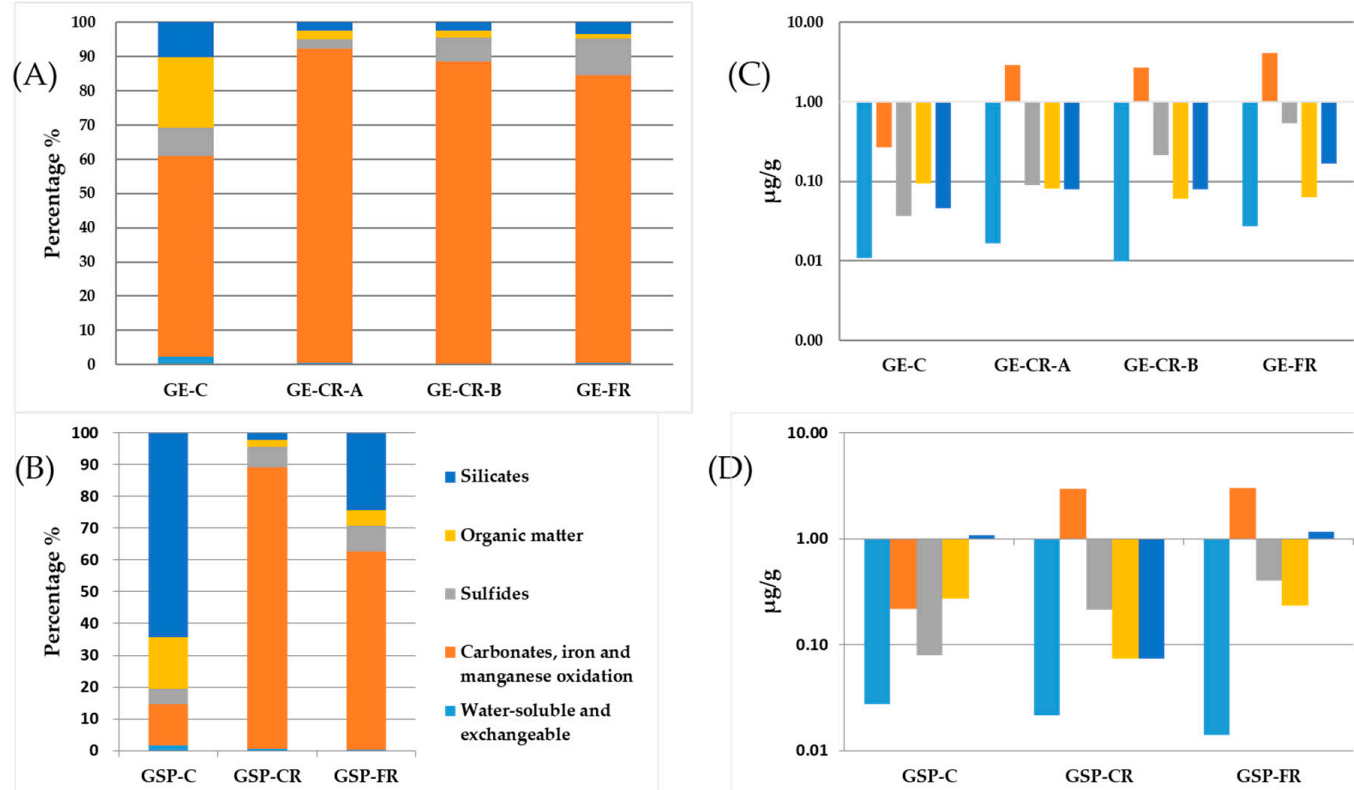

(D)

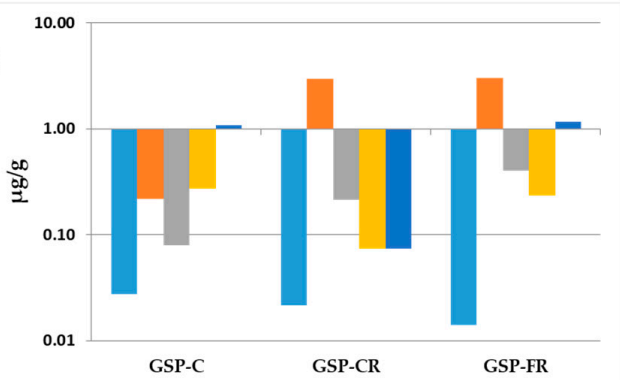

Figure 9. Sequential chemical leaching results for beryllium: $(\mathbf{A}, \mathbf{B})$ percentage leached; and $(\mathbf{C}, \mathbf{D})$ the concentration in leachates.

Beryllium is a semi-volatile element during coal gasification and combustion processes. Thus, it seems unreasonable that the concentration of Be in the GSP-CR was higher than that in the GSP-FR 
(Table 4). However, this phenomenon may be possible due to the complicated conditions in the entrained flow slagging gasifier [11]. Perhaps the different mode of occurrence of Be in the GE-C and GSP-C influenced its behavior during GE and GSP gasification processes (Figure 9A,B).

\section{Vanadium (V)}

The literature indicates that $\mathrm{V}$ in coal is probably associated with the clays and that some may be organically bound [37,69]. Liu et al. [34] concluded that V is mainly associated with the organic matter and to a lesser extent is present in illite or mixed-layer illite/smectite. Roscoelite

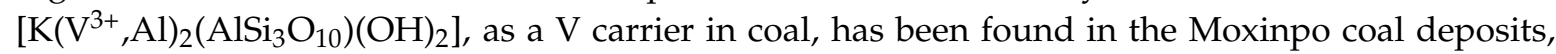
Chongqing, China [79]. The results of sequential chemical leaching for vanadium is shown in Figure 10. In GE-C, about $40 \%$ was associated with the carbonates and iron and manganese oxides, with $30 \%$ of the $\mathrm{V}$ being present in the silicates and $20 \%$ associated with the sulfides (Figure 10A). The organically-associated V was only about $10 \%$ (Figure 10A). In GSP-C, almost $60 \%$ of the V was present in the silicates. The carbonates and iron and manganese oxides and the organics each contained almost $15 \%$ of the V (Figure 10B).

After the coal gasification processes the proportion of $\mathrm{V}$ associated with the carbonates and iron and manganese oxides in the coarse residues was about $80 \%$ and the $\mathrm{V}$ in organic association in the residues was less than $5 \%$ (Figure 10A,B). In the fine residues $\mathrm{V}$ in the carbonates and iron and manganese oxides was still dominant at about $60 \%$ (Figure 10A,B). According to the proportion and concentration of V associated with the silicates in the GSP-C, GSP-CR, and GSP-FR samples, V in the silicates could be released upon heating, but then is combined with the carbonates in the residues. However, some V could still be fixed by silicates in the residues, especially the fine residue (GSP-FR).

Vanadium is a semi-volatile trace element during the coal gasification and combustion processes $[6,12]$. However, the concentration of V in the GSP-CR was higher than that in the GSP-FR (Table 4). This phenomenon is possible due to the complicated conditions in the entrained flow slagging gasifier [11]. Perhaps the different modes of occurrence of V in the GE-C and GSP-C influenced its release behavior during the GE and GSP gasification processes (Figure 10A,B).
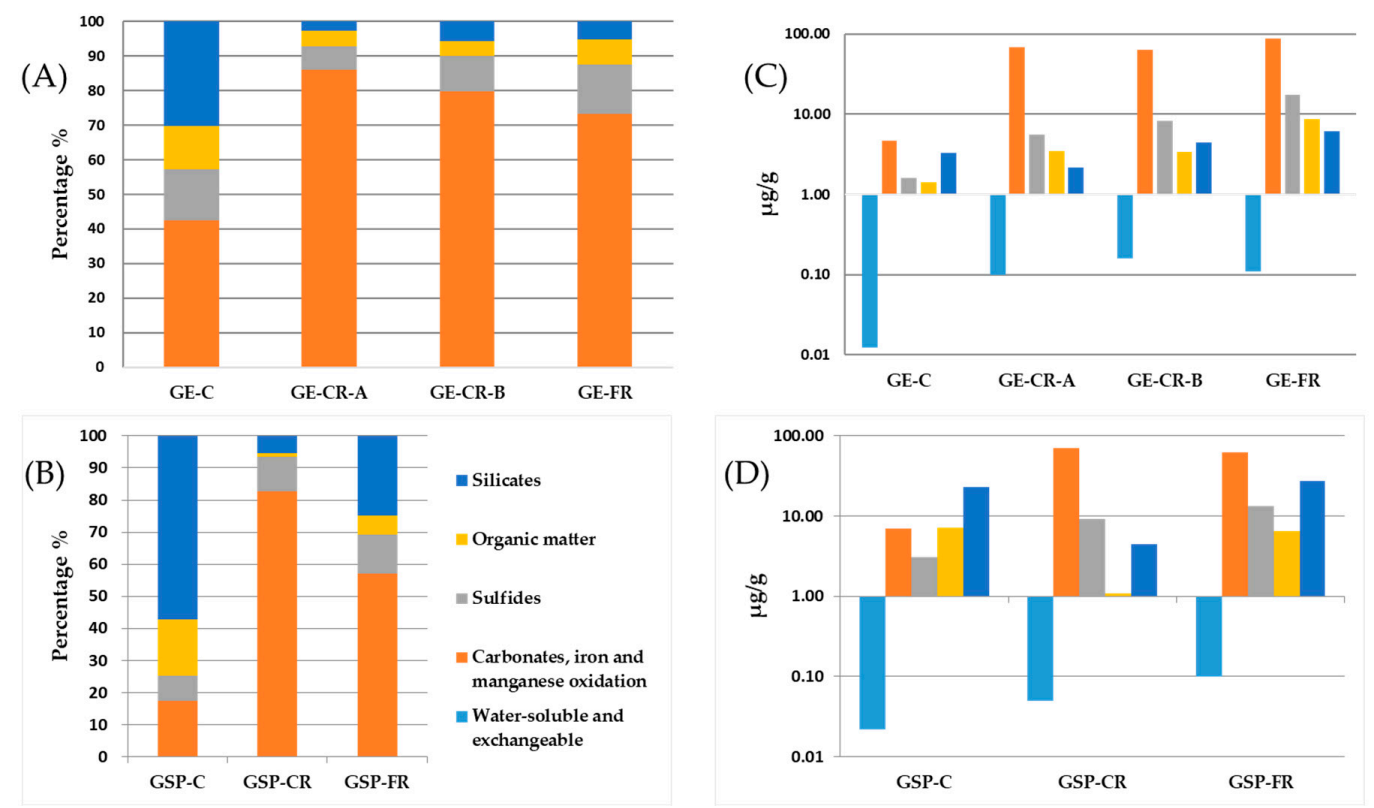

Figure 10. Sequential chemical leaching results for vanadium: $(\mathbf{A}, \mathbf{B})$ percentage leached; and $(\mathbf{C}, \mathbf{D})$ the concentration in leachates. 


\section{Copper $(\mathrm{Cu})$}

Copper occurs in different modes of occurrence in coals. Swaine [69] states that copper is likely to be present in coal as chalcopyrite or other sulfides, or as organically-bound species, especially in low-rank coals. Riley et al. [19] indicate that $\mathrm{Cu}$ is found in silicates, sulfides, and residual matter (organic, shielded, or resistate minerals) in the Australian Cur coal. Dai et al. [80] showed that Cu in a high-U coal mainly occurs in selenides, such as krutatie $\left(\mathrm{CuSe}_{2}\right)$ and eskebornite $\left(\mathrm{CuFeSe}_{2}\right)$.

From the results of sequential chemical leaching for copper shown in Figure 11, almost 80\% of the $\mathrm{Cu}$ in the GE-C was present in the silicates. The $\mathrm{Cu}$ associated with the sulfides and the organic matter was less than $5 \%$ each (Figure 11A). In the GSP-C, more than $60 \%$ of the $\mathrm{Cu}$ was associated with the silicates (Figure 11B), with more than $30 \%$ organically bound.

$$
\text { (A) }
$$

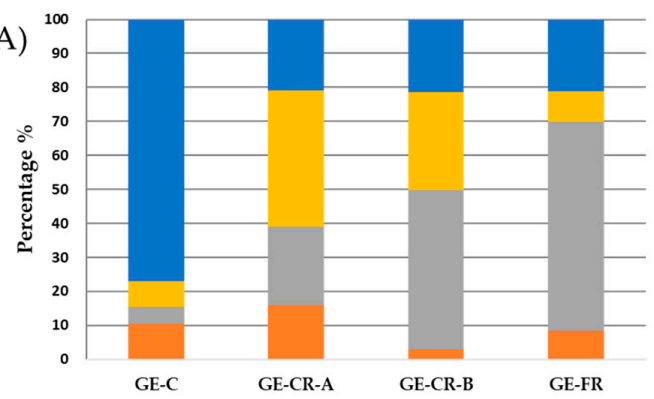

(B)

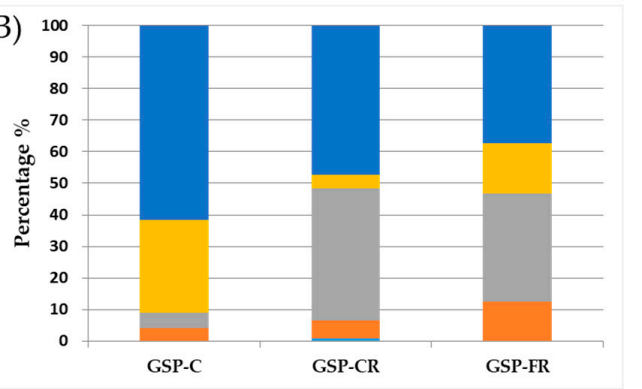

(C)

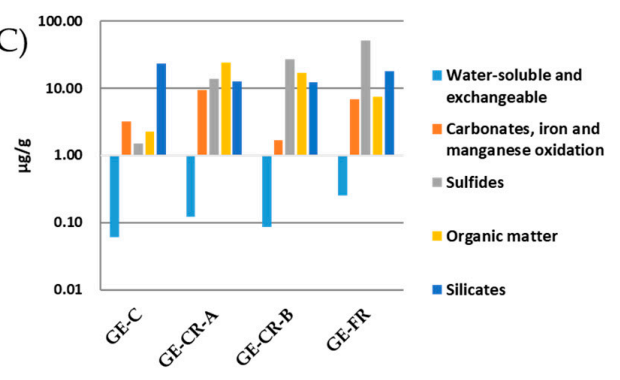

(D)

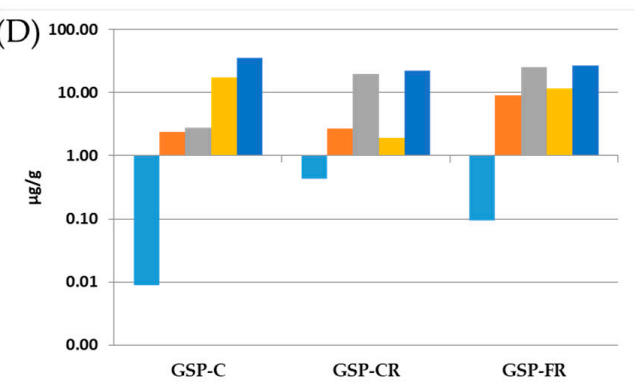

Figure 11. Sequential chemical leaching results for copper: $(\mathbf{A}, \mathbf{B})$ percentage leached; and $(\mathbf{C}, \mathbf{D})$ the concentration in leachates.

After the coal gasification processes, silicate-bound $\mathrm{Cu}$ in the residues produced from the GE gasification process was about $20 \%$ (Figure 11A). Although $\mathrm{Cu}$ in the silicates could be released upon heating some $\mathrm{Cu}$ could still be fixed by silicates in the residues. In addition, proportions of $\mathrm{Cu}$ associated with the organic matter and the sulfides in the GE residues significantly increased compared to that in the GE-C (Figure 11A), indicating that $\mathrm{Cu}$ tended to combine with the sulfides or organic matter during the liquid slag cooling. In the GSP residues, more than $40 \%$ of the Cu could be fixed by the silicates in the residues, with $30-40 \%$ in the GSP residues tending to combine with the sulfides (Figure 12B).

According to the classifications proposed by Clarke [6] and Hower et al. [12], $\mathrm{Cu}$ is a semi-volatile trace element during coal gasification and combustion processes. However, $\mathrm{Cu}$ was depleted in both the GSP and GE residues in our study (Figure 5). The different behavior of $\mathrm{Cu}$ in the combustor from that in the gasifier may result from the reducing environment in the gasifiers. Yoshiie et al. [11] and Helble et al. [61] suggest that reducing environments may promote trace element volatility to some extent. Trace elements released from minerals or organic matter upon heating in the gasifiers may be captured by the liquid slags resulting from the molten ash. The modes of occurrence of trace elements in the feed coals could affect their volatilities while the modes of occurrence of trace elements in the gasification residues may, in turn, reflect their tendency of combining with different components during the liquid slag cooling. 
(A)

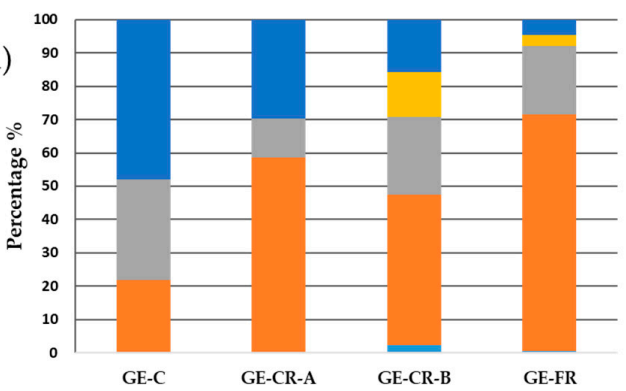

(B)

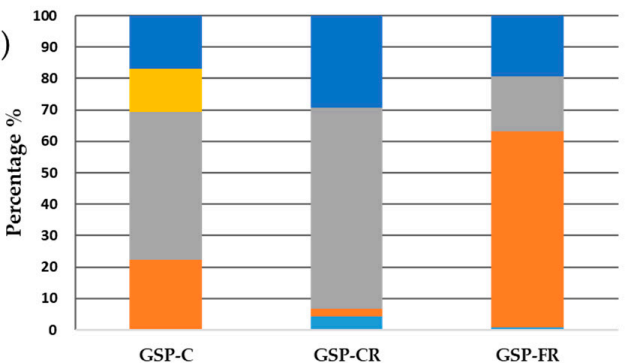

(C)

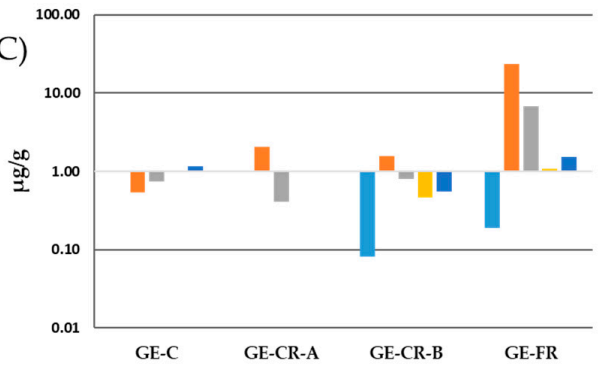

(D)

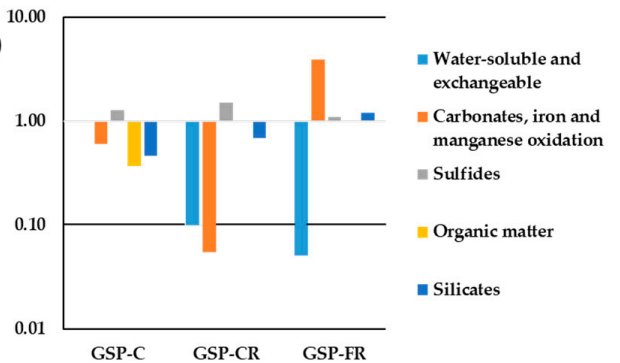

Figure 12. Sequential chemical leaching results for arsenic: $(\mathbf{A}, \mathbf{B})$ percentage leached; and $(\mathbf{C}, \mathbf{D})$ the concentration in leachates.

\subsubsection{Volatilization-Condensation Behavior of Trace Elements}

Trace elements As and Se showed volatilization-condensation behavior in both the GE and GSP gasification processes.

Arsenic (As)

Arsenic is also of particular concern due to its toxicity. Finkelman [68] proposes a confidence level of 8 out 10 that As is most likely present in pyrite in coal, with a possible minor amount organically bound. Swaine [69] indicates that As may also be present as arsenate ions in clays and phosphate minerals. Huggins and Huffman [81] used a combination of sequential leaching and XAFS on a bituminous coal concluding that arsenate is the species leached by $\mathrm{HCl}$ and that $\mathrm{As}$ in pyrite is leached by $\mathrm{HNO}_{3}$. Yudovich and Ketris [82] reviewed As in coal and indicate that there are three dominant forms, e.g., pyritic, organic, and arsenate. Dai et al. $[67,83]$ report that As in coals is mainly associated with pyrite. Kolker et al. [84] summarizes As in coal and reports that lower rank coals generally have a larger proportion of organically-bound arsenic.

Sequential chemical leaching results for arsenic in this study is shown in Figure 12. In GE-C, more than $40 \%$ of the As was in the silicates (likely kaolinite), which was the main mode of occurrence. In addition, almost $40 \%$ of the As was determined to be in the sulfides (likely pyrite) and about $20 \%$ was associated with the carbonates and iron and manganese oxides (likely calcite, or oxidized species) (Figure 12A). In the GSP-C, more than $40 \%$ of the As was present in the sulfides (likely pyrite), with about $20 \%$ was in the carbonates and iron and manganese oxides (likely calcite, or oxidized species) and $20 \%$ was present in the silicates. The proportion of organically-bound As in the GSP-C was only about $10 \%$ (Figure 12B).

After the coal gasification processes, the proportion of As associated with the silicates in the GE-C sample compared to the GE gasification residues gradually decreased (Figure 12A). This indicates that As in the silicates could be released during heating in the GE gasifier. The proportion of As in sulfides in the GE-C compared to the GE gasification residues showed no remarkable change. However, the proportion of As associated with the carbonates and iron and manganese oxides significantly increased from the GE-C to the GE gasification residues. In the GSP-CR, about $60 \%$ of the As was associated with the sulfides. Arsenic associated with the sulfides in the fine residues may be from the unreacted coal particles which retain a small amount of pyrite due to the short reactor residence time of the 
fine residues. However, the sulfide-bound As in the GSP-CR may transform from other modes of occurrence. In the GSP-FR, more than $60 \%$ of the As was determined to be in the carbonates and iron and manganese oxides (Figure 12B), indicating that some As could combine with the carbonates and iron and manganese oxides after being captured by the liquid slags. The As in the silicates in the GSP residues was about $20 \%$.

According to the volatile classifications of trace elements during coal combustion and gasification processes proposed by Clarke [6] and Hower et al. [12], arsenic is between volatile and semi-volatile. In our study As was depleted in the coarse residues, but enriched in the fine residues (Figure 5), which was in accord with volatilization-condensation mechanism. During the coal gasification process As tended to vaporize with heating and then condense on the finer particles during the gas cooling process. Arsenic was released with the fracture of char particles at high temperatures in the gasifiers and then was absorbed on the surface layer of the finer particles, which contain more residual carbon and greater surface areas [6,9-11]. Previous investigations indicated that the coarse residues contain more glassy material compared with the fine residues [85-88]. In entrained flow slagging gasifiers, the temperature is higher than the ash fusion temperature of the feed coal, thus, mineral matter in the feed coal converts to ash, which will rapidly become liquid slag. Crystalline structures will develop if these liquid phases cool slowly, while a mixture of glassy material will be formed with rapid cooling of the liquid slags. Trace elements would be captured by liquid drops or absorbed by ash particles. The modes of occurrence of As in the gasification residues indicate that As tended to combine with the carbonates and iron and manganese oxides or the sulfides. Fine residues in the gasification process are similar to fly ash in the coal combustion process. However, they contain more residual carbon which could absorb trace elements easily. Liquid phases cool slowly in the fine residues compared with the coarse residues. The minerals, such as calcite, could recrystallize downstream. Studies report that hematite and pyrrhotite are the products of pyrite in coal gasification [89-94]. Thus, it is reasonable that As in the fine residues is principally associated with carbonates and iron and manganese oxides (likely calcite and hematite). The As identified in the sulfides is probably associated with the pyrrhotite (note that pyrrhotite not identified by XRD may still be present in low concentrations) [19].

\section{Selenium (Se)}

Selenium in coals could occur in organic matter, in pyrite and in other sulfides. Dreher and Finkelman [95] investigated the modes of occurrence of selenium in an ash-rich upper zone of a sub-bituminous coal and identified seven modes of occurrence of selenium: water-soluble, ion exchangeable, galena and lead selenide, clays and silicates, pyrite, and organically-associated. Dai et al. [96] report that Pb-bearing selenide and sulfide minerals contributed to the Se content in the No. 6 Coal (Pennsylvanian) in the Junger Coalfield, Ordos Basin, China. Finkelman [37] reports that most Se in the low-rank coals is organically bound, with small proportions being present in the sulfides and silicate phases.

The results of sequential chemical leaching for selenium are shown in Figure 13. Selenium in the two feed coals was entirely present in sulfides (likely pyrite). In the GE coarse residues, Se had two modes of occurrence. About $80 \%$ of the Se in GE-CR-A and 60\% in GE-CR-B was associated with the silicates, with $20 \%$ and $40 \%$, respectively, in the sulfides (Figure 13A). Selenium associated with the sulfides in the GE-FR was higher than that in the GE-C (Figure 13C), indicating that some Se released from the sulfides could be captured by liquid slags and combined with the silicates when the liquid slags cool. In the GE-FR, 50\% of the Se was associated with the organic matter (Figure 13A). Since there was no organically-bound Se determined in the GE-C this phenomenon can be explained by some Se being absorbed by the residual carbon in the fine residues which has a high volume area ratio $[6,11]$. In the GSP-CR, more than $60 \%$ of the Se was associated with the organic matter, with $25 \%$ being present in the silicates and no more than $5 \%$ of the Se associated with the sulfides (Figure 13B). In the GSP-FR, almost 70\% of the Se was in the silicates, with 25\% sulfide-associated (Figure 13B). 
According to the volatile classifications of trace elements during coal combustion and gasification processes proposed by Clarke [6] and Hower et al. [12], Se is volatile. In our study Se was depleted in the coarse residues whereas it was enriched in the fine residues (Figure 5), which is in accord with the volatilization-condensation mechanism.

(A)

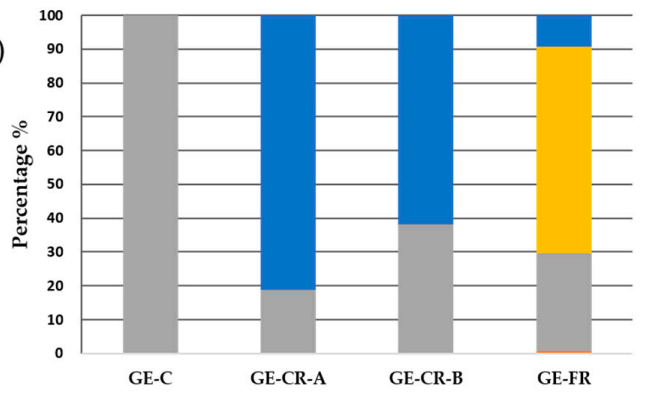

(B)

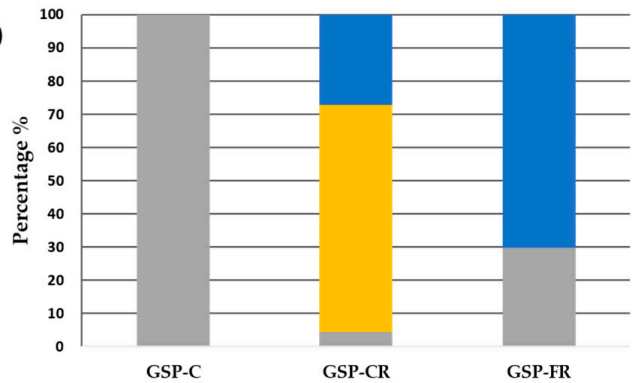

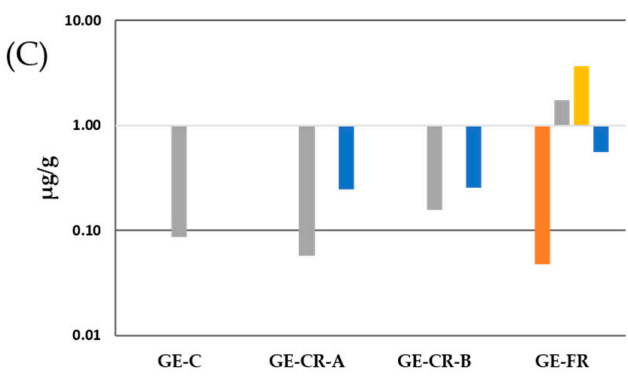

(D)

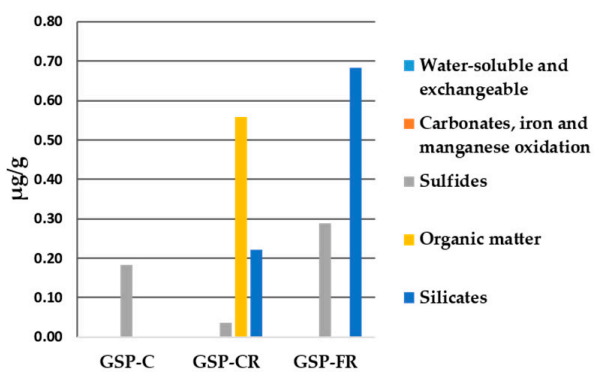

Figure 13. Sequential chemical leaching results for selenium: $(\mathbf{A}, \mathbf{B})$ percentage leached; and $(\mathbf{C}, \mathbf{D})$ the concentration in leachates.

\subsubsection{Other Trace Elements}

Results from the GE gasification process indicated that $\mathrm{Cr}, \mathrm{Cd}, \mathrm{U}, \mathrm{Ni}, \mathrm{Pb}, \mathrm{Sb}, \mathrm{Zn}$, and $\mathrm{Tl}$ show volatile behavior (Figure 6). During the GSP gasification process $\mathrm{Cd}, \mathrm{Pb}, \mathrm{Sb}, \mathrm{Zn}$, and $\mathrm{Tl}$, as well as Co during the GE gasification process, all plotted in part (D), showing volatilization-condensation behavior and during the GSP gasification process $\mathrm{Co}, \mathrm{Cr}$, U, and Ni plotted in Part (C), showing enrichment in both fine and coarse residues.

\section{Chromium $(\mathrm{Cr})$}

Chromium could be associated with clays in the coal and spinel group minerals, such as chromite. Swaine [69] states that organically-associated $\mathrm{Cr}$ is suspect, but reports that it is reasonable to expect some organically-bound $\mathrm{Cr}$ in low-rank coals. Huggins and Huffman [81] indicate that in most American bituminous coals, only two major forms of $\mathrm{Cr}$ exist: $\mathrm{Cr}^{3+}$ in organic association and $\mathrm{Cr}^{3+}$ in illite. Finkelman [37] reports that $\mathrm{Cr}$ has similar modes of occurrences in bituminous coals and in low-rank coals but one difference is that there may be more ion-exchangeable chromium in the low-rank coal clays.

The results of sequential chemical leaching for chromium are shown in Figure 14. In the feed coals, four modes of occurrences of $\mathrm{Cr}$ were determined. About $50 \%$ of the $\mathrm{Cr}$ in the GE-C was organically-associated and about $20 \%$ of the $\mathrm{Cr}$ was present each in the silicates, carbonates, and iron and manganese oxides. (Figure 14A). In the GSP-C, more than $60 \%$ of the $\mathrm{Cr}$ was identified in the silicates (likely kaolinite), with about 20\% associated with the organic matter (Figure 14A). In Figure 5, Cr plotted in Part (A), showing volatile behavior during the GE gasification process, but plotted in Part (C), showing enrichment in GSP-CR and GSP-FR. This can be explained by the modes of occurrences of $\mathrm{Cr}$ in the feed coals affecting its behavior during gasification processes (Figure 14A,B). 
After the coal gasification processes, the proportion of $\mathrm{Cr}$ present in the carbonates and iron and manganese oxides in the coarse residues was about $80-90 \%$ (Figure 14A,B). This indicated that during the slag cooling process, $\mathrm{Cr}$ captured by the liquid slags tended to combine with the carbonates and iron and manganese oxides (likely calcite or some oxidized species). Although the proportion of $\mathrm{Cr}$ associated with the sulfides showed no remarkable change, the concentrations of sulfide-associated $\mathrm{Cr}$ increased from the feed coals to the gasification coarse residues (Figure 14C,D). In the GE-FR, more than $60 \%$ of the $\mathrm{Cr}$ was in the carbonates and iron and manganese oxides (likely calcite or some oxidized species), while about 70\% of the Cr was in the sulfides in the GSP-FR (Figure 14A,B). Tang et al. [40] showed that spinel was identified in the gasification residues, but Cr-bearing spinel was not determined by SEM-EDX due to the low concentration of $\mathrm{Cr}$. In this study, $\mathrm{Cr}$ identified in the carbonates and iron and manganese oxides is probably associated with spinel (note that spinel was not identified by XRD or SEM-EDX).

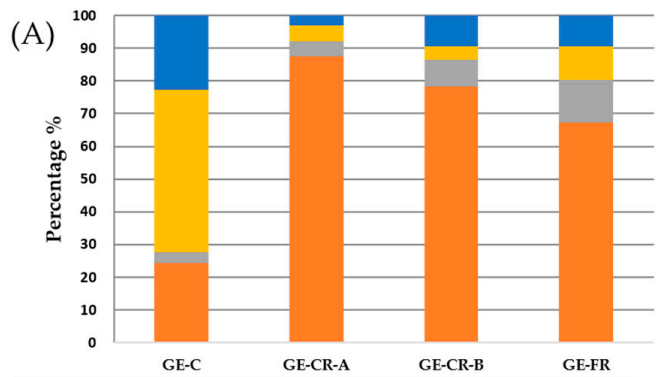

(C)
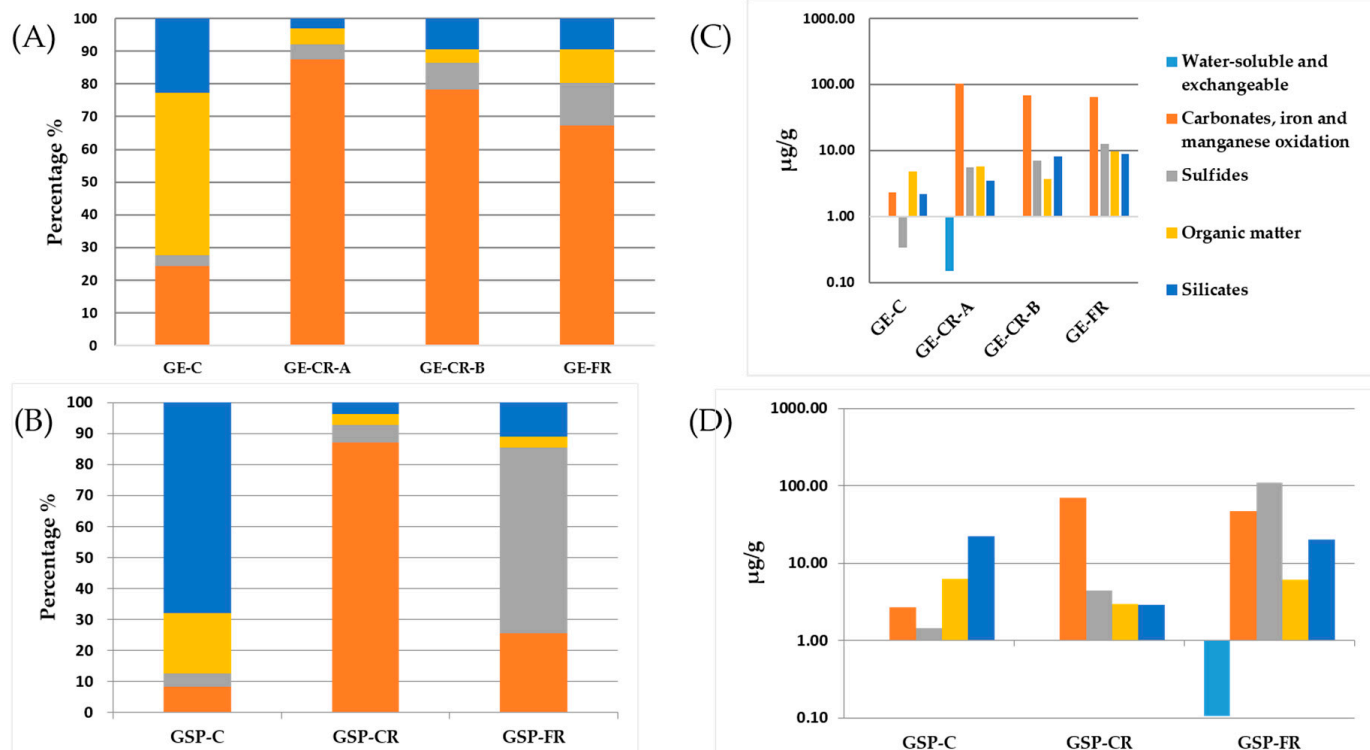

(D)

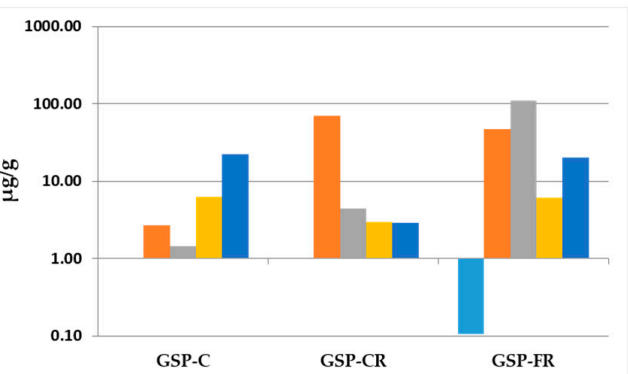

Figure 14. Sequential chemical leaching results for chromium: $(\mathbf{A}, \mathbf{B})$ percentage leached; and $(\mathbf{C}, \mathbf{D})$ the concentration in leachates.

Uranium (U)

Much of the U in coal appears to be organically-bound. Swaine [69] suggests that U could be present in both the mineral matter and the organic matter, one difference is that the $U$ in the organics is presumably more volatile. Finkelman [37] reports that, in high-rank coals, $40 \%$ of the U is associated with the silicates, while $55 \%$ of the $U$ in the low rank coals is organically-associated.

The results of sequential chemical leaching for uranium is shown in Figure 15. Although five modes of occurrences of $U$ were determined in the feed coals, the concentration of $U$ in each mode of occurrence was low. In the GSP-C, about 70\% of the U was in the silicates (likely kaolinite). After coal gasification the proportion of $U$ associated with the carbonates and iron and manganese oxides in the GE gasification residues was more than $80 \%$ (Figure 15A). This indicated that U captured by the liquid slag tended to combine with the carbonates and iron and manganese oxides (likely calcite or some oxidized species) during the slag cooling process. In the GSP-C, more than 70\% was in the silicates (Figure 15B). In the GSP gasification residues, about $50 \%$ of the $U$ was associated with the carbonates and iron and manganese oxides (Figure 15B), which was the main mode of occurrence in the residues. In Figure 5, U plotted in Part (A), showing volatile behavior during the GE gasification process, but plotted in Part (C), showing enrichment in GSP-CR and GSP-FR. This can be explained by the modes of occurrences of $U$ in the feed coals affecting its behavior during gasification processes (Figure 15A,B). 

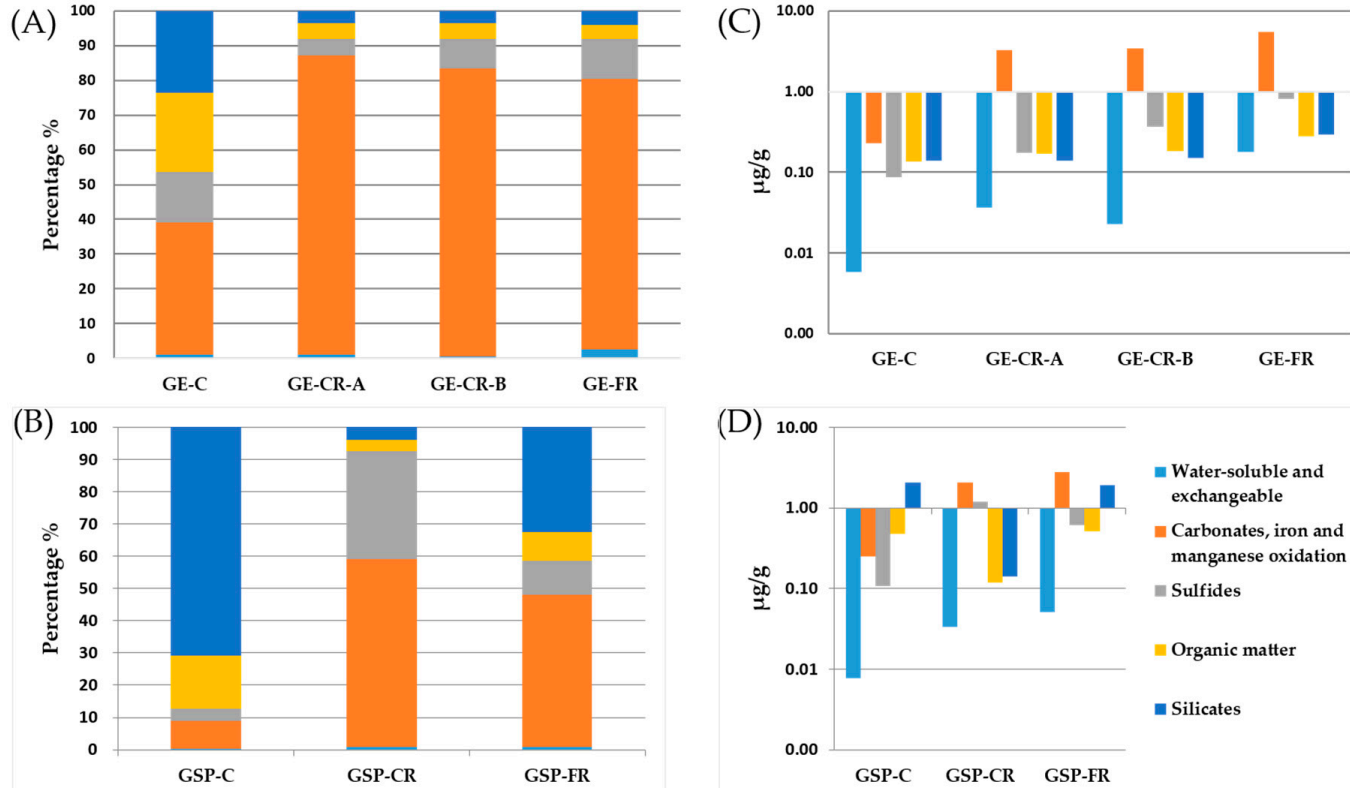

Figure 15. Sequential chemical leaching results for uranium: $(\mathbf{A}, \mathbf{B})$ percentage leached; and $(\mathbf{C}, \mathbf{D})$ the concentration in leachates.

Nickel (Ni)

It was reported that nickel in coal may be in organic association and inorganically-associated nickel in coal may be with the pyrite [97]. However, the confidence level of $\mathrm{Ni}$ being present in organic matter or associated with sulfides is only 2 out of 10 [68]. Finkelman [37] reports that $30 \%$ of the $\mathrm{Ni}$ is associated with the clays in high-rank coals while $30 \%$ is organically-bound and $30 \%$ is in the monosulfides, sulfates, and carbonates in low-rank coals, respectively.

The results of sequential chemical leaching for nickel are shown in Figure 16. In GE-C, more than $40 \%$ of the $\mathrm{Ni}$ was associated with the $\mathrm{HCl}$-soluble minerals (probably monosulfides and calcite), with about $25 \%$ organically-bound (Figure 16A). In GSP-C, almost $50 \%$ of the Ni was associated with organic matter and about $40 \%$ was present in the silicates (clay crystal lattice, or kaolinite). In Figure 5, Ni plotted in Part (A), showing volatile behavior during the GE gasification process, but plotted in Part (C), showing enrichment in GSP-CR and GSP-FR. This can be explained by the modes of occurrences of $\mathrm{Ni}$ in the feed coals affecting its behavior during gasification processes (Figure 16A,B). After the coal gasification processes, $70-80 \%$ of the $\mathrm{Ni}$ was in the carbonates and iron and manganese oxides (likely calcite or some oxidized species) in GE-CR-A, GE-CR-B, GE-FR, and GSP-CR, but in the GSP-FR more than $60 \%$ was sulfide-associated. The concentration of Ni associated with the sulfides from the feed coals to the residues increased (Figure 16C,D), indicating that the sulfide-associated Ni may be transformed from other modes of occurrence.

Cobalt (Co)

The mode of occurrence of cobalt in coals is still uncertain. Finkelman [68] indicates that cobalt is most likely associated with sulfides minerals, but also occurs in clays and in the organic matter (the confidence level is 4 of 10). Swaine [69] suggested that some cobalt may be associated with organic matter. Riley et al. [17] report that Co is distributed across all the modes of occurrence. Dai et al. [83] report an unusual mode of occurrence of cobalt (cattierite: CoS) in Late Permian anthracite. Finkelman et al. [37] propose that in high-rank coals $35 \%$ of the Co is in monosulfides, while $30 \%$ is in pyrite and chalcopyrite. 

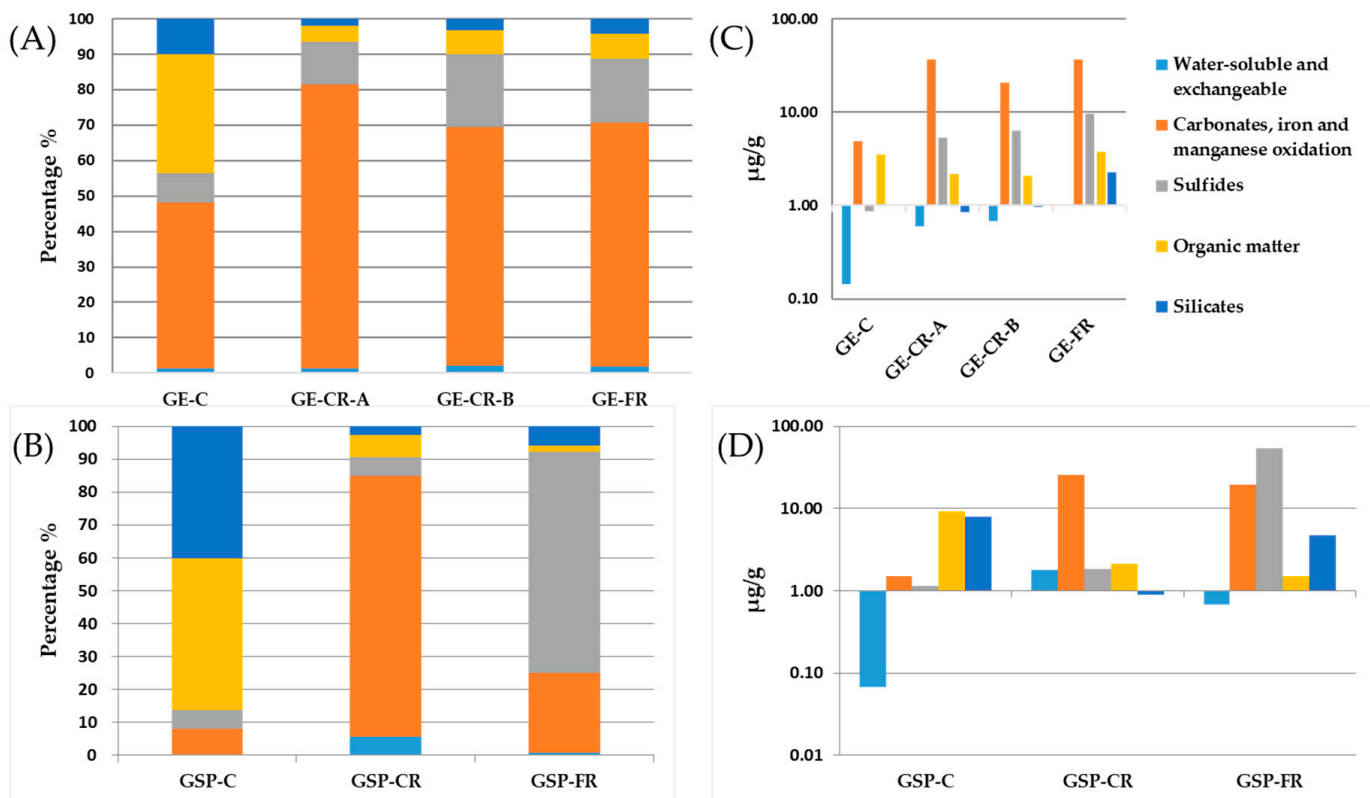

Figure 16. Sequential chemical leaching results for nickel: $(\mathbf{A}, \mathbf{B})$ percentage leached; and $(\mathbf{C}, \mathbf{D})$ the concentration in leachates.

The results of sequential chemical leaching for cobalt are shown in Figure 17. In the GE-C, almost $70 \%$ of the Co was associated with the carbonates, iron and manganese oxides, with about $20 \%$ being present in the organic matter (Figure 17A). In the GSP-C, the silicate-associated Co was about 50\%, the organically-bound Co was about $30 \%$ and the proportion associated with the carbonates and iron and manganese oxides was about 10\% (Figure 17B). After the coal gasification processes, the proportion of $\mathrm{Co}$ associated with the carbonates and iron and manganese oxides in the coarse residues was about $80-90 \%$ and in the fine residues about $60-80 \%$. This indicated that Co captured by the liquid slags tended to combine with the carbonates and iron and manganese oxides during liquid slag cooling. The concentration of sulfide-associated Co in the residues was more than that in the feed coals, indicating that some Co associated with the sulfides may be transformed from other modes of occurrences (Figure 17C,D).

\section{Cadmium $(\mathrm{Cd})$}

Finkelman [68] reports that $\mathrm{Cd}$ is predominantly associated with sphalerite ( $\mathrm{ZnS})$ and the confidence level is 8 of 10. Goodarzi [98] reports that $\mathrm{Cd}$ is associated with sphalerite in Canadian feed coals. Finkelman [37] reports that $65 \%$ of the $\mathrm{Cd}$ is in sphalerite in high-rank coals and $80 \%$ in low-rank coals.

From the results of sequential chemical extraction in this study (Figure 18), it can be seen that $\mathrm{Cd}$ had five modes of occurrence in the feed coals and gasification residues, but the concentration of the extracted $\mathrm{Cd}$ in each mode of occurrence was low. In the GE-C, about $50 \%$ of the $\mathrm{Cd}$ was associated with carbonates and iron and manganese oxides (calcite) and more than $40 \%$ of the $\mathrm{Cd}$ in the GSP-C was present in silicates (clays, or kaolinite).

After the coal gasification processes, $50 \%$ of the $\mathrm{Cd}$ in the GE-CR-A was present in carbonates, iron and manganese oxides, (probably calcite, or oxidized species) and more than $20 \%$ was associated with the silicates (probably Al-Si glass, gehlenite, or melilite) (Figure 18A). In the GE-CR-B, about $30 \%$ of the $\mathrm{Cd}$ was associated with the carbonates and iron and manganese oxides (probably calcite, or oxidized species), and more than $20 \%$ was organically-bound. The proportion of silicate-bound $\mathrm{Cd}$ in the GE-CE-B was more than 10\%, which was probably associated with the Al-Si glass, clays crystal lattice, or kaolinite. In the GE-FR, about $40 \%$ of the Cd was associated with sulfides and 
carbonates, iron and manganese oxides, respectively (Figure 18A). In the GSP-CR, almost 30\% was associated with the silicates, with $25 \%$ associated with carbonates and iron and manganese oxides (Figure 18B). In the GSP-FR, 40\% of the Cd was present in the carbonates and iron and manganese oxides and 30\% was sulfide-associated. The silicate-associated Cd accounts for almost 20\% (Figure 18B). In the coarse residues, $\mathrm{Cd}$ captured by liquid slags tended to combine with the carbonates, iron and manganese oxides, silicates, and organic matter, but in the fine residues, Cd captured by liquid slags tended to combine with the carbonates and iron and manganese oxides and the sulfides during liquid slag cooling.
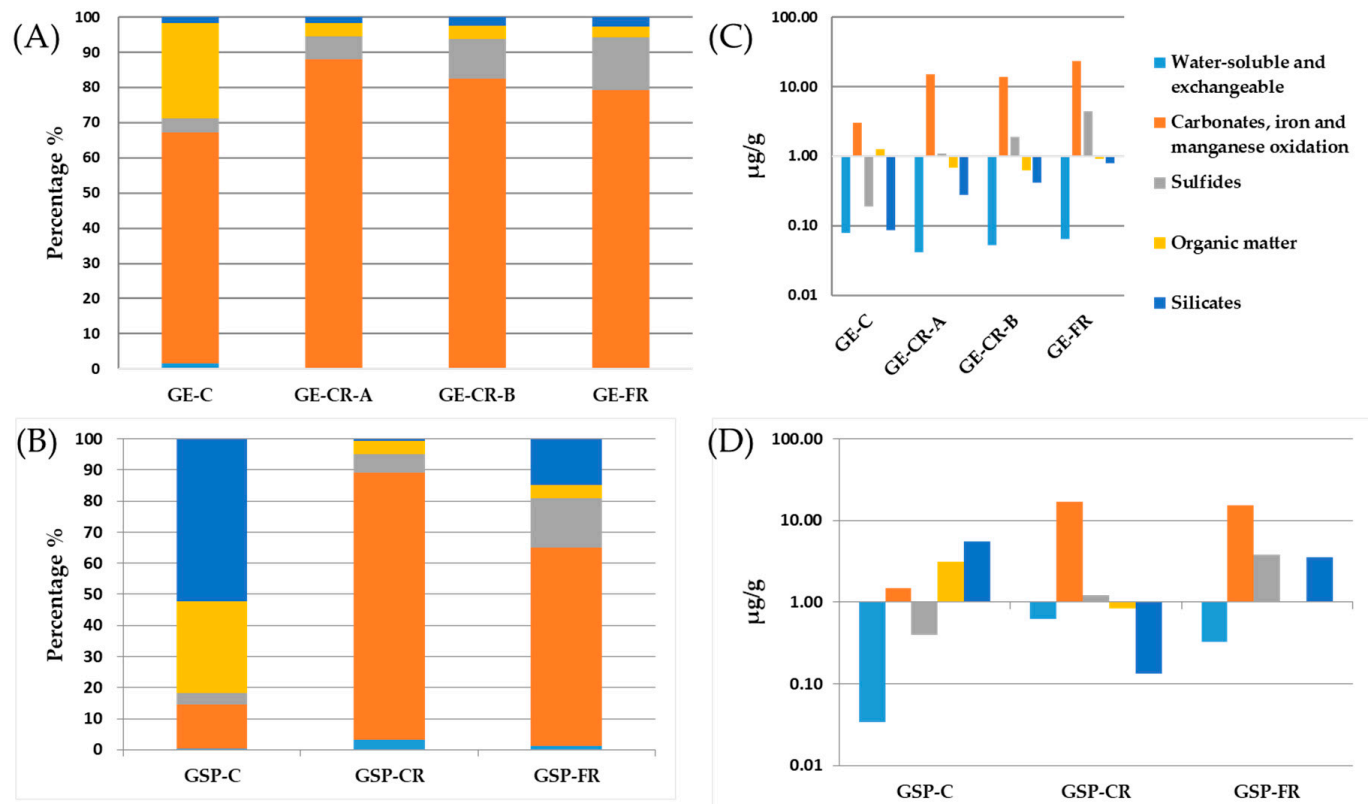

Figure 17. Sequential chemical leaching results for cobalt: $(\mathbf{A}, \mathbf{B})$ percentage leached; and $(\mathbf{C}, \mathbf{D})$ the concentration in leachates.
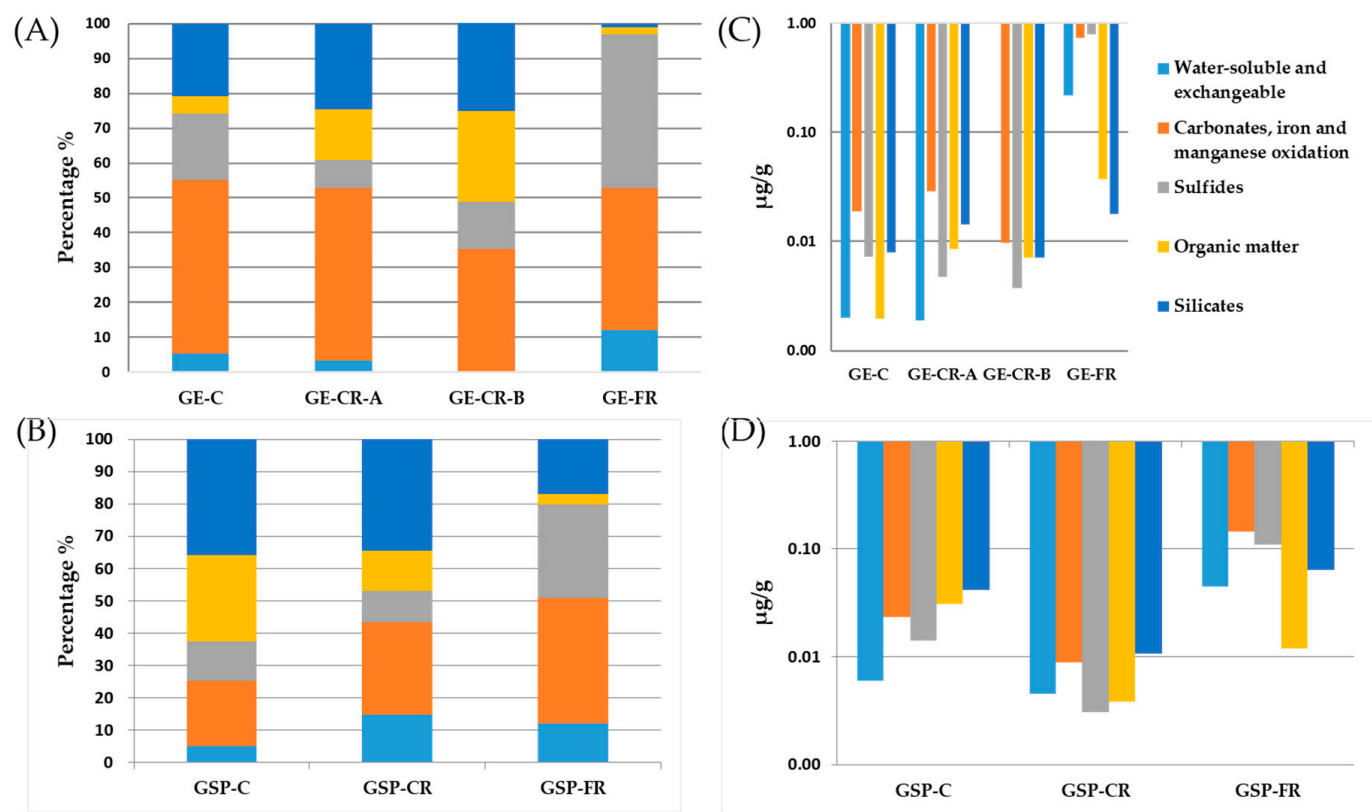

Figure 18. Sequential chemical leaching results for cadmium: $(\mathbf{A}, \mathbf{B})$ percentage leached; and $(\mathbf{C}, \mathbf{D})$ the concentration in leachates. 
Lead (Lead)

Lead in coal is inorganically bound. Swaine [69] suggests that lead may occur in pyrite and in organic association in low-rank coals. Finkelman [68] proposes that the confidence level of $\mathrm{Pb}$ being in sulfides (galena) and sulfide minerals is 8 of 10. Hower and Robertson [99] indicate that some $\mathrm{Pb}$ is associated with lead selenide (PbSe). Dai et al. [96] report that Pb-bearing selenide and sulfide minerals contributed to $\mathrm{Pb}$ content in No. $6 \mathrm{Coal}$ (Pennsylvanian) in the Junger Coalfield, Ordos Basin, China.

The results of sequential chemical extraction for lead are shown in Figure 19. In the GE-C, almost $60 \%$ of the $\mathrm{Pb}$ was associated with the carbonates and iron and manganese oxides. The proportion of silicate-bound $\mathrm{Pb}$ was about $20 \%$ and the proportion of sulfide-associated $\mathrm{Pb}$ was about $10 \%$. After the $\mathrm{GE}$ gasification process, the proportion of $\mathrm{Pb}$ present in the carbonates and iron and manganese oxides in the GE gasification residues was about $50-70 \%$ (Figure 19A). The concentration of $\mathrm{Pb}$ associated with the carbonates and iron and manganese oxides was highest in the GE-FR (Figure 20C). In the GSP-C, almost $40 \%$ of the $\mathrm{Pb}$ was in the carbonates (likely calcite), iron and manganese oxides and about $10 \%$ was in the silicates, sulfides and the organic matter, respectively (Figure 19B). After the GSP gasification process, the proportion of $\mathrm{Pb}$ associated with the carbonates and iron and manganese oxides was the highest among all the modes of occurrences of $\mathrm{Pb}$. This indicates that $\mathrm{Pb}$ captured by the liquid slags tended to combine with the carbonates and iron and manganese oxides primarily during the liquid slag cooling process.
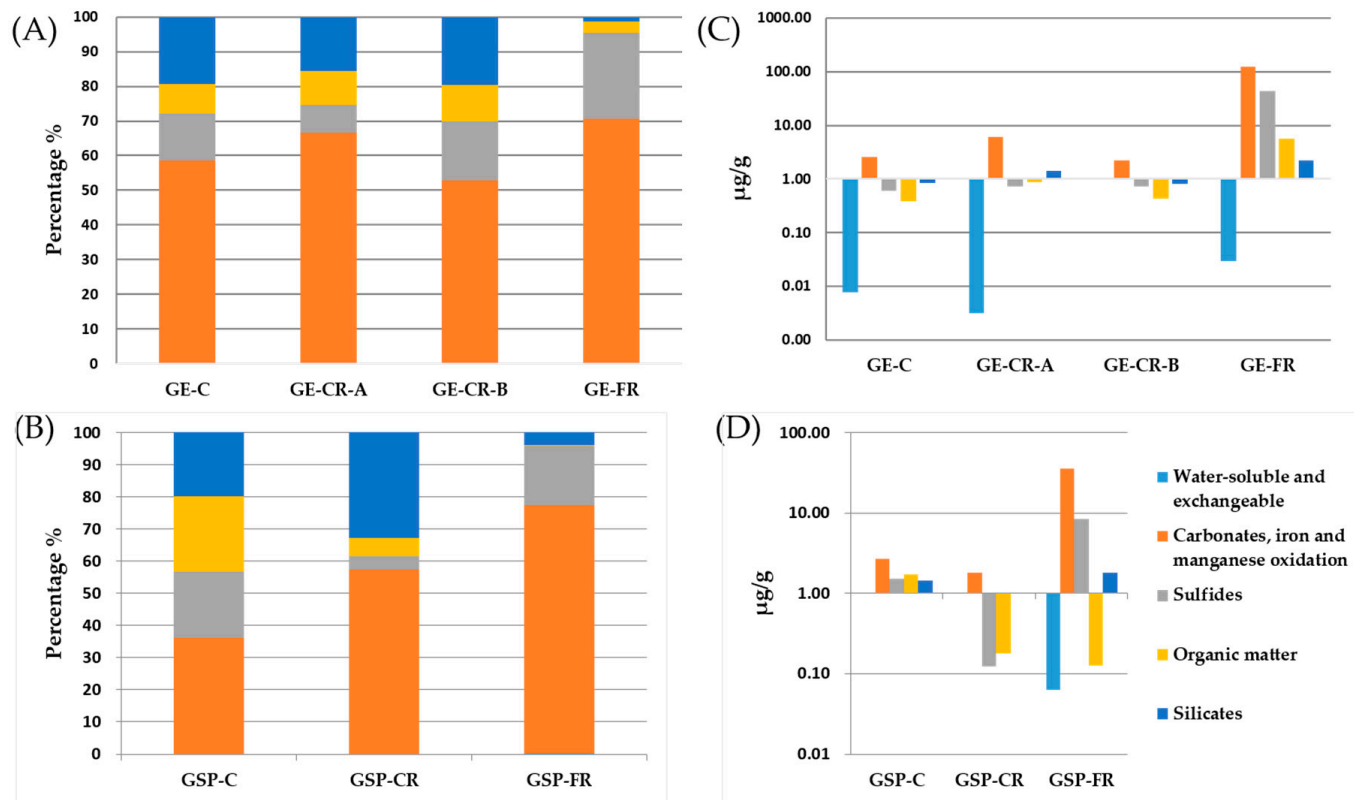

Figure 19. Sequential chemical leaching results for lead: $(\mathbf{A}, \mathbf{B})$ percentage leached; and $(\mathbf{C}, \mathbf{D})$ the concentration in leachates.

\section{Antimony (Sb)}

Swaine [69] indicates that $\mathrm{Sb}$ could be associated with the sulfides and the organic matter in coal. Finkelman [68] suggests that $\mathrm{Sb}$ could be present in pyrite and as accessory sulfides, e.g., stibnite, which is dispersed in the organic matter. In the investigation by Riley et al. [19], Sb was found in the silicates and in the organics. Dai et al. [39,83] indicates that Sb occurs in getchllite and pyrite. Finkelman [37] reports that $55 \%$ of the $\mathrm{Sb}$ is sulfide-associated and $25 \%$ is silicate-associated in high-rank coals, but in low-rank coals, $50 \%$ of the $\mathrm{Sb}$ is in the silicates.

The sequential leaching results for antimony are shown in Figure 20. In the GE-C, five modes of occurrence of $\mathrm{Sb}$ were found. The proportion of $\mathrm{Sb}$ associated with the carbonates and iron and manganese oxides was about $40 \%$ and more than $35 \%$ was with the silicates. Notably, more than 
$20 \%$ of the $\mathrm{Sb}$ was water-soluble and exchangeable, although the concentration of $\mathrm{Sb}$ in this mode of occurrence was low (Figure 20A,C). After the gasification processes, about 50-60\% of the Sb was in the carbonates and iron and manganese oxides in the GE-CR-A and the GSP-CR (Figure 20A,B). The proportion of $\mathrm{Sb}$ associated with the silicates in the GE-CR-B, GE-FR and GSP-FR was about 60-80\%. This indicated that $\mathrm{Sb}$ captured by the liquid slags tended to primarily combine with the Al-Si glass or perhaps the original silicate-bound Sb showed less volatility during the GE and GSP gasification processes. According to the volatility classifications of trace elements during coal combustion and gasification proposed by Clarke [6] and Hower [12], Sb is semi-volatile. But in this study, Sb plotted in Part (A), showing volatility during the GE gasification process while plotting in part (D), showing volatilization-condensation behavior during the GSP gasification process. From the proportion of $\mathrm{Sb}$ associated with the silicates, it could be seen that $\mathrm{Sb}$ fixed in the silicates was released, but tended to combine with the silicates, carbonates, and the iron and manganese oxides during liquid slag cooling.
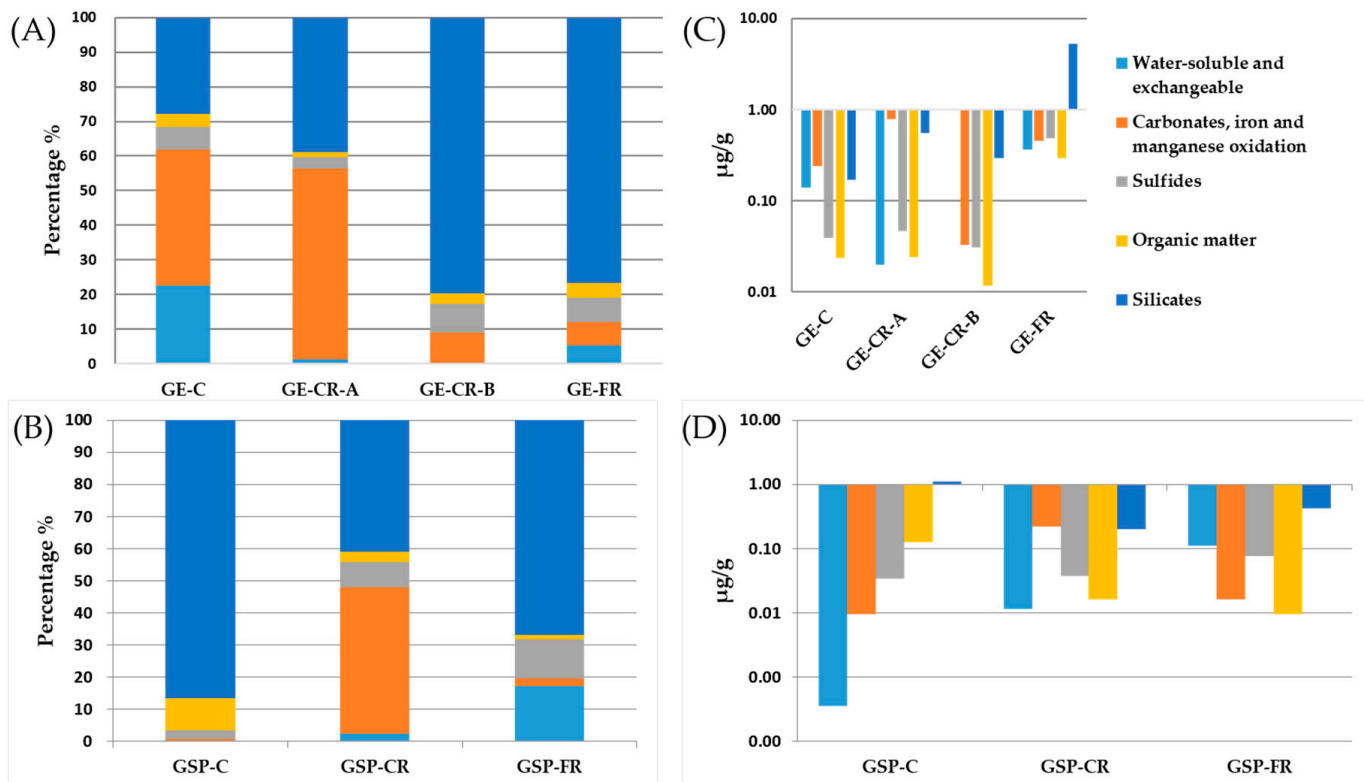

Figure 20. Sequential chemical leaching results for antimony: $(\mathbf{A}, \mathbf{B})$ percentage leached; and $(\mathbf{C}, \mathbf{D})$ the concentration in leachates.

Zinc (Zn)

Swain [69] proposes that $\mathrm{Zn}$ in coals is primarily associated with sphalerite but organic binding in low-rank coals is also a possibility. Finkelman [68] gives a high confidence level of 8 out of 10 for $\mathrm{Zn}$ associated with sphalerite. Riley et al. [19] report that some of the $\mathrm{Zn}$ in the Australian coals is predominantly present as $\mathrm{ZnO}$, with a lesser fraction in the clays (illite) and some $\mathrm{Zn}$ is associated with the silicates and sphalerite. Finkelman [37] reports that $45 \%$ of the $\mathrm{Zn}$ is present in the sphalerite in high-rank coals and $55 \%$ in low-rank coals.

The results of sequential chemical leaching for zinc are shown in Figure 21. In our study five modes of occurrence of $\mathrm{Zn}$ could be found in the GE-C. The proportion of $\mathrm{Zn}$ associated with the carbonates and iron and manganese oxides and the silicates was almost $40 \%$ each. The proportion of $\mathrm{Zn}$ present in the organic matter and water-soluble and exchangeable forms was almost $10 \%$, respectively (Figure 21A). In the GSP-C, about $60 \%$ of the $\mathrm{Zn}$ was associated with the silicates (clays, e.g., kaolinite) and $20 \%$ present in the carbonates and iron and manganese oxides. The proportion of $\mathrm{Zn}$ associated with the organic matter and sulfides was almost $10 \%$ each (Figure 21B).

After the gasification processes, $\mathrm{Zn}$ in the GE-CR-A was predominantly associated with the carbonates and iron and manganese oxides, accounting for about $80 \%$ (Figure 21A). In the GE-CR-B, 
the proportion of $\mathrm{Zn}$ present in carbonates and iron and manganese oxides was almost $40 \%$, and almost 30\% in the organic matter and the silicates (Figure 21A). In the GE-FR, almost $60 \%$ of the Zn was associated with the carbonates and iron and manganese oxide and more than 30\% was associated with the sulfides (Figure 21A). In the GSP-CR, more than 50\% of the Zn was in the silicates with the concentration of $\mathrm{Zn}$ associated with the silicates in the GSP-FR lower than that in the GSP-C (Figure 21D). This indicated that $\mathrm{Zn}$ fixed in the silicates showed less volatile behavior compared to other modes of occurrences of $\mathrm{Zn}$. The proportion of $\mathrm{Zn}$ determined in the carbonates and iron and manganese oxides was about $30 \%$ and almost $20 \%$ in the water-soluble and exchangeable forms. The water-soluble $\mathrm{Zn}$ found in the GSP-CR may be due to external moisture from the quench system when collecting the coarse residues. In the GSP-FR the proportion of $\mathrm{Zn}$ present in the carbonates and iron and manganese oxides was almost $60 \%$ and the sulfide-associated and silicate-associated $\mathrm{Zn}$ was about $20 \%$ each (Figure 21B). On the whole, Zn captured by the liquid slags tended to combine with the carbonates and iron and manganese oxides and the silicates and sulfides in the gasification residues during liquid slag cooling.
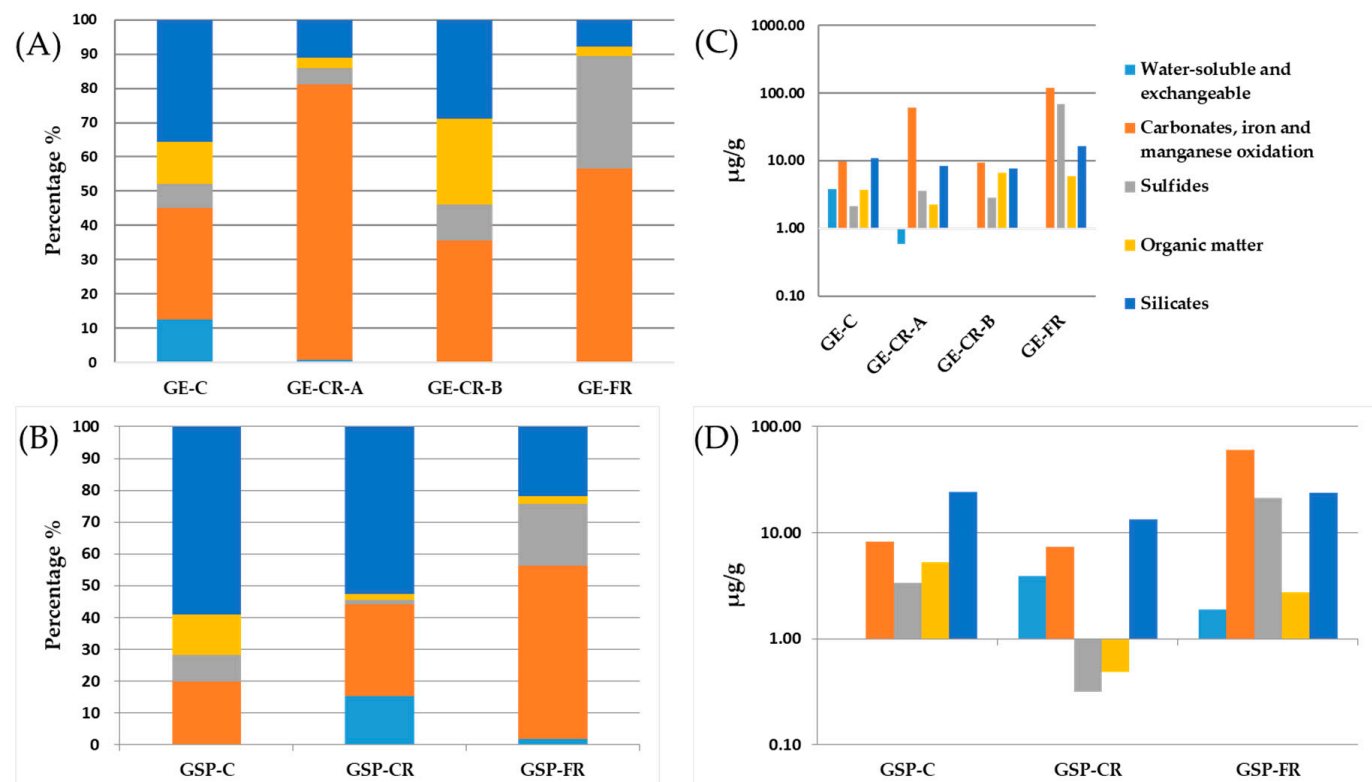

Figure 21. Sequential chemical leaching results for zinc, $(\mathbf{A}, \mathbf{B})$ percentage leached; and $(\mathbf{C}, \mathbf{D})$ the concentration in leachates.

Thallium (Tl)

Finkelman [68] concludes that the confidence level of Tl associated with pyrite is low, 4 out of 10. Thallium associated with the organic matter was identified in Australian coals [19].

From the results of sequential chemical leaching for thallium (Figure 22), it is seen that the proportion of $\mathrm{Tl}$ associated with the sulfides in the GE-C was almost $60 \%$ and about $20 \%$ each was silicate-bound and organically-associated. After the GE gasification process, the proportion of $\mathrm{Tl}$ in the GE gasification residues associated with the organic matter increased accounting for about $40-50 \%$ (Figure 22A). Notably, there was about $20-30 \%$ of the $\mathrm{Tl}$ in water-soluble and exchangeable forms in the GE gasification residues. Attention should be paid to the handling and deposition of gasification residues due to the water-soluble Tl having possible negative impacts on soil, water and human health. In the GSP-C, the organically-associated Tl was predominant, accounting for about $90 \%$ (Figure 22B). After the GSP gasification process the proportion of $\mathrm{Tl}$ associated with the carbonates and iron and manganese oxides was about $40 \%$ in the GSP gasification residues. The proportion of $\mathrm{Tl}$ in water-soluble and exchangeable forms increased significantly, accounting for almost $20 \%$ in the 
GSP-CR and 60\% in the GSP-FR (Figure 22B). Although the concentration of $\mathrm{Tl}$ in water-soluble and exchangeable forms was low in this study, the potential accumulative effect of gasification residues on soil and water should be evaluated.

(A)

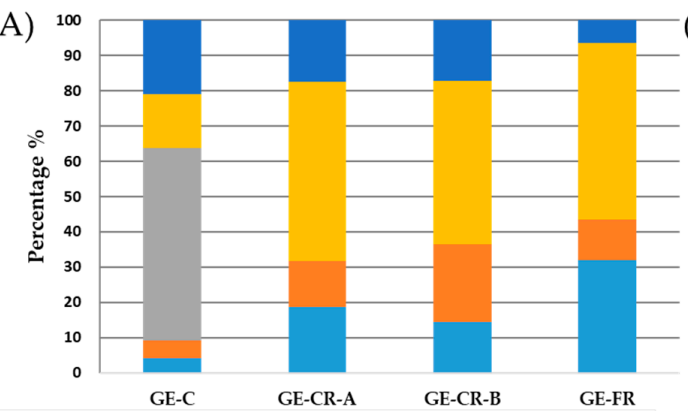

(B)

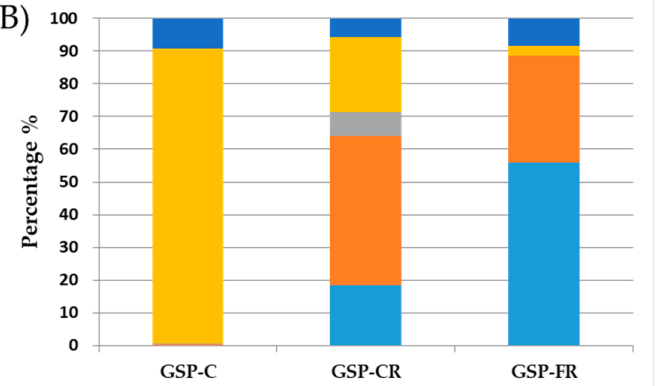

(C)

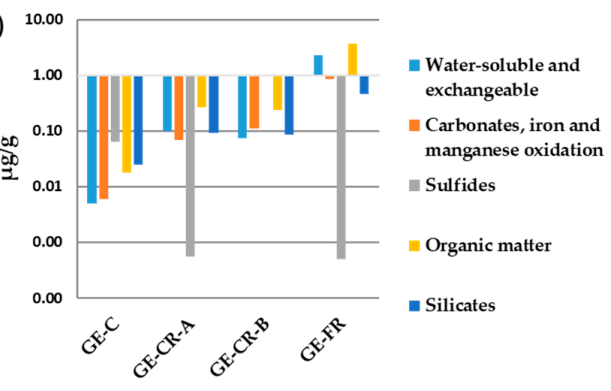

(D)

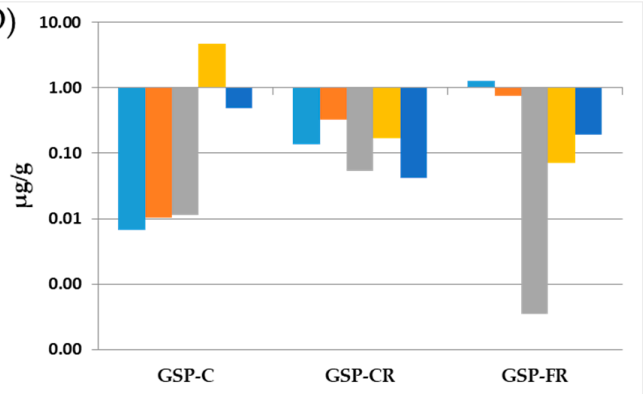

Figure 22. Sequential chemical leaching results for thallium: $(\mathbf{A}, \mathbf{B})$ percentage leached; and $(\mathbf{C}, \mathbf{D})$ the concentration in leachates.

\section{Conclusions}

The modes of occurrence of trace elements in the feed coals influenced their volatilities during coal gasification. Based on the relative enrichment of trace elements in the residues, $\mathrm{Hg}, \mathrm{Mo}, \mathrm{Ba}, \mathrm{Be}, \mathrm{V}$, and $\mathrm{Cu}$ showed volatile behavior during the GE and GSP gasification processes; As and Se showed volatilization-condensation behavior during the GE and GSP gasification processes; $\mathrm{Cr}, \mathrm{Cd}, \mathrm{U}, \mathrm{Ni}, \mathrm{Pb}$, $\mathrm{Sb}, \mathrm{Zn}$, and $\mathrm{Tl}$ showed volatility during the GE gasification process; $\mathrm{Cd}, \mathrm{Pb}, \mathrm{Sb}, \mathrm{Zn}$, and $\mathrm{Tl}$ in the GSP samples, as well as $\mathrm{Co}$ in the GE samples, showed volatilization-condensation behavior; and $\mathrm{Co}, \mathrm{Cr}, \mathrm{U}$, and Ni showed less volatility during the GSP gasification process.

Although trace elements, such as $\mathrm{Hg}$, Mo, $\mathrm{Ba}, \mathrm{Be}, \mathrm{V}, \mathrm{Cu}$, As, and Se, had different modes of occurrence in the GE-C and the GSP-C, they showed consistent volatile behavior during the GE and GSP gasification processes. As a whole, the proportion of trace elements, such as $\mathrm{Cr}, \mathrm{U}, \mathrm{Ni}, \mathrm{Co}, \mathrm{Cd}$, $\mathrm{Sb}$, and $\mathrm{Zn}$ associated with the silicates in GSP-C was higher than that in the GE-C, resulting in lower volatility of these elements during the GSP gasification process. Compared with the behavior of trace elements in coal combustion, $\mathrm{Mo}, \mathrm{Ba}, \mathrm{Be}, \mathrm{V}$, and $\mathrm{Cu}$ were more volatile during gasification. Although the proportion of trace elements $\mathrm{Cd}, \mathrm{Pb}, \mathrm{Sb}, \mathrm{Zn}$, and $\mathrm{Tl}$ associated with the silicates in GSP-C were higher compared to that in the GE-C, these trace elements were still semi-volatile during GSP gasification, showing volatilization-condensation behavior.

Behavior of trace elements during coal gasification included their release upon heating, capture by the liquid slags, and their final combination with components in the slag upon cooling. After entrained flow gasification, carbonates, and iron and manganese oxides (likely recrystallized calcite) were the main hosts of most trace elements in the residues, including $\mathrm{As}, \mathrm{Ba}, \mathrm{Be}, \mathrm{Cr}, \mathrm{Co}, \mathrm{Cd}, \mathrm{Hg}, \mathrm{Ni}, \mathrm{Pb}, \mathrm{Tl}, \mathrm{V}, \mathrm{U}$, and $\mathrm{Zn}$. Copper, Se, Cd, Sb, and Zn tended to stay in the Al-Si glass. Molybdenum likely combined with the sulfides in the residues. In addition, some portion of $\mathrm{Tl}$ was present in water-soluble and exchangeable forms. Although the concentration of $\mathrm{Tl}$ in water-soluble and exchangeable forms was 
low, the accumulative effect of gasification residues for the soil and the underground water should be considered.

Comparing the modes of occurrences of $\mathrm{Cr}, \mathrm{U}, \mathrm{Ni}$, and $\mathrm{Co}$ in GE-C and GSP-C, it is obvious that these trace elements in GE-C were associated with the organic matter and the carbonates, iron and manganese oxides, or the sulfides while a substantial amount of these elements were associated with the silicates in GSP-C. This is the likely reason why $\mathrm{Cr}, \mathrm{U}, \mathrm{Ni}$, and $\mathrm{Co}$ showed more volatile behavior during the GE gasification process compared to the GSP gasification process. Thus, we can conclude that the modes of occurrences of $\mathrm{Cr}, \mathrm{U}, \mathrm{Ni}$, and Co play important roles in their behavior during coal gasification. Trace elements associated with the silicates had a tendency to stay in the coarse residues which contained more inorganic matter than the fine residues.

Author Contributions: Yuegang Tang and Xi Pan conceived and designed the experiments; Xi Pan and Yafeng Wang performed the experiments; Xin Guo and Xi Pan analyzed the data; Binbin Huan provided the samples; Robert B. Finkelman and Shaoqing Wang contributed the article corrections; and Xin Guo wrote the paper.

Acknowledgments: The authors gratefully acknowledge the financial and other support from the National Key Basic Research Program of China (no. 2014CB238905) and 111 project (no. B17042). The authors also express special and sincere thanks to Shifeng Dai for his kind constructive suggestions. The authors would like to express great gratitude to Jianrong Yang for his assistance with sampling. We appreciate the help of the Analytical Laboratory of Beijing Research Institute of Uranium Geology, Shanxi Coal Geological Bureau and the State Key Laboratory of Coal Resources and Safe Mining (CUMTB) for their testing work.

Conflicts of Interest: The authors declare no conflict of interest.

\section{References}

1. Finkelman, R.B.; Tian, L. The health impacts of coal use in China. Int. Geol. Rev. 2018, 60, 579-589. [CrossRef]

2. Liu, S.; Qi, C.; Jiang, Z.; Zhang, Y.; Niu, M.; Li, Y.; Dai, S.; Finkelman, R.B. Mineralogy and geochemistry of ash and slag from coal gasification in China: A review. Int. Geol. Rev. 2018, 60, 717-735. [CrossRef]

3. Kronbauer, M.A.; Izquierdo, M.; Dai, S.; Waanders, F.B.; Wagner, N.J.; Mastalerz, M.; Hower, J.C.; Oliveira, M.L.S.; Taffarel, S.R.; Bizani, D.; et al. Geochemistry of ultra-fine and nano-compounds in coal gasification ashes: A synoptic view. Sci. Total Environ. 2013, 456, 95-103. [CrossRef] [PubMed]

4. $\quad$ Bunt, J.R.; Waanders, F.B. Volatile trace element behaviour in the Sasol ${ }^{\circledR}$, fixed-bed dry-bottom (FBDB ${ }^{\mathrm{TM}}$ gasifier treating coals of different rank. Fuel Process. Technol. 2011, 92, 1646-1655. [CrossRef]

5. Oboirien, B.O.; Thulari, V.; North, B.C. Enrichment of trace elements in bottom ash from coal oxy-combustion: Effect of coal types. Appl. Energy 2016, 177, 81-86. [CrossRef]

6. Clarke, L.B. The fate of trace elements during coal combustion and gasification: An overview. Fuel 1993, 72, 731-736. [CrossRef]

7. Ward, C.R. Analysis and significance of mineral matter in coal seams. Int. J. Coal Geol. 2002, 50, 135-168. [CrossRef]

8. Xu, M.; Yan, R.; Zheng, C.; Qiao, Y.; Han, J.; Sheng, C. Status of trace element emission in a coal combustion process: A review. Fuel Process. Technol. 2004, 85, 215-237. [CrossRef]

9. Martinez, M.R. The fate of trace elements and bulk minerals in pulverized coal combustion in a power station. Fuel Process. Technol. 1996, 47, 79-92. [CrossRef]

10. Jankowski, J.; Ward, C.R.; French, D.; Groves, S. Mobility of trace elements from selected Australian fly ashes and its potential impact on aquatic ecosystems. Fuel 2006, 85, 243-256. [CrossRef]

11. Yoshiie, R.; Taya, Y.; Ichiyanagi, T.; Ueki, Y.; Naruse, I. Emissions of particles and trace elements from coal gasification. Fuel 2013, 108, 67-72. [CrossRef]

12. Hower, J.C.; Henke, K.R.; Dai, S.; Ward, C.R.; French, D.; Liu, S.; Graham, U.M. Chapter 2-Generation and nature of coal fly ash and bottom ash. Coal Combust. Prod. 2017, 21-65. [CrossRef]

13. Hower, J.C.; Groppo, J.G.; Graham, U.M.; Ward, C.R.; Kostova, I.; Maroto-Valer, M.M.; Dai, S. Coal-derived unburned carbons in fly ash: A review. Int. J. Coal Geol. 2017, 197, 11-27. [CrossRef]

14. Bartoňová, L. Unburned carbon from coal combustion ash: An overview. Fuel Process. Technol. 2015, 134, 136-158. [CrossRef]

15. Asl, S.M.H.; Ghadi, A.; Baei, M.S.; Javadian, H.; Maghsudi, M.; Kazemian, H. Porous catalysts fabricated from coal fly ash as cost-effective alternatives for industrial applications: A review. Fuel 2018, 217, 320-342. 
16. Yao, Z.; Ji, X.; Sarker, P.K.; Tang, J.; Ge, L.; Xia, M. A comprehensive review on the applications of coal fly ash. Earth-Sci. Rev. 2015, 141, 105-121. [CrossRef]

17. Querol, X.; Fernández-Turiel, J.; López-Soler, A. Trace elements in coal and their behaviour during combustion in a large power station. Fuel 1995, 74, 331-343. [CrossRef]

18. Dai, S.; Seredin, V.V.; Ward, C.R.; Jiang, J.; Hower, J.C.; Song, X.; Jiang, Y.; Wang, X.; Gornostaeva, T.; $\mathrm{Li}, \mathrm{X}$; et al. Composition and modes of occurrence of minerals and elements in coal combustion products derived from high-Ge coals. Int. J. Coal Geol. 2014, 121, 79-97. [CrossRef]

19. Riley, K.W.; French, D.H.; Farrell, O.P.; Wood, R.A.; Huggins, F.E. Modes of occurrence of trace and minor elements in some Australian coals. Int. J. Coal Geol. 2012, 94, 214-224. [CrossRef]

20. Finkelman, R.B. Modes of Occurrence of Environmentally-Sensitive Trace Elements in Coal; Springer: Cham, The Netherlands, 1995; pp. 24-50.

21. Nordberg, M.; Nordberg, G.F. Trace element research-historical and future aspects. J. Trace Elem. Med. Biol. 2016, 38, 46-52. [CrossRef] [PubMed]

22. Dai, S.; Finkelman, R.B. Coal as a promising source of critical elements: Progress and future prospects. Int. J. Coal Geol. 2018, 186, 155-164. [CrossRef]

23. Dai, S.; Yan, X.; Ward, C.R.; Hower, J.C.; Zhao, L.; Wang, X.; Zhao, L.; Ren, D.; Finkelman, R.B. Valuable elements in Chinese coals: A review. Int. Geol. Rev. 2018, 60, 590-620. [CrossRef]

24. Seredin, V.V.; Dai, S.; Sun, Y.; Chekryzhov, I.Y. Coal deposits as promising sources of rare metals for alternative power and energy-efficient technologies. Appl. Geochem. 2013, 31, 1-11. [CrossRef]

25. Bunt, J.R.; Waanders, F.B. Trace element behaviour in the Sasol-Lurgi MK IV FBDB gasifier. Part 1-The volatile elements: $\mathrm{Hg}$, As, Se, Cd and Pb. Fuel 2008, 81, 75-89. [CrossRef]

26. Bunt, J.R.; Waanders, F.B. Trace element behaviour in the Sasol-Lurgi MK IV FBDB gasifier. Part 2-The semi-volatile elements: Cu, Mo, Ni and Zn. Fuel 2009, 88, 961-969. [CrossRef]

27. Bunt, J.R.; Waanders, F.B. Trace element behaviour in the sasol-lurgi fixed-bed dry-bottom gasifier. Part 3-The non-volatile elements: Ba, Co, Cr, Mn and V. Fuel 2010, 89, 537-548. [CrossRef]

28. Thompson, B.B. Thermodynamic equilibrium study of trace element mobilisation under air blown gasification conditions. Fuel 2000, 81, 75-89.

29. Díaz-Somoano, M.; Martínez-Tarazona, M.R. Trace element evaporation during coal gasification based on a thermodynamic equilibrium calculation approach. Fuel 2003, 82, 137-145. [CrossRef]

30. Li, H.; Yoshihiko, N.; Dong, Z.; Zhang, M. Application of the FactSage to Predict the Ash Melting Behavior in Reducing Conditions. Chin. J. Chem. Eng. 2006, 14, 784-789. [CrossRef]

31. Konttinen, J.; Backman, R.; Hupa, M.; Moilanen, A.; Kurkela, E. Trace element behavior in the fluidized bed gasification of solid recovered fuels-A thermodynamic study. Fuel 2013, 106, 621-631. [CrossRef]

32. Querol, X.; Klika, Z.; Weiss, Z.; Finkelman, R.B.; Alastuey, A.; Juan, R. Determination of element affinities by density fractionation of bulk coal samples. Fuel 2001, 80, 83-96. [CrossRef]

33. Dai, S.; Li, D.; Ren, D.; Tang, Y.; Shao, L.; Song, H. Geochemistry of the late Permian No. 30 coal seam, Zhijin Coalfield of Southwest China: Influence of a siliceous low-temperature hydrothermal fluid. Appl. Geochem. 2004, 19, 1315-1330. [CrossRef]

34. Liu, J.; Yang, Z.; Yan, X.; Ji, D.; Yang, Y.; Hu, L. Modes of occurrence of highly-elevated trace elements in superhigh-organic-sulfur coals. Fuel 2015, 156, 190-197. [CrossRef]

35. Spears, D.A. The use of laser ablation inductively coupled plasma-mass spectrometry (LA ICP-MS) for the analysis of fly ash. Fuel 2004, 83, 1765-1770. [CrossRef]

36. Spears, D.A. The determination of trace element distributions in coals using sequential chemical leaching-A new approach to an old method. Fuel 2013, 114, 31-37. [CrossRef]

37. Finkelman, R.B.; Palmer, C.A.; Wang, P. Quantification of the modes of occurrence of 42 elements in coal. Int. J. Coal Geol. 2018, 185, 138-160. [CrossRef]

38. Liu, J.; Ward, C.R.; Graham, I.T.; French, D.; Dai, S.; Song, X. Modes of occurrence of non-mineral inorganic elements in lignites from the Mile Basin, Yunnan Province, China. Fuel 2018, 222, 146-155. [CrossRef]

39. Tang, Y.; Wang, Y.; Huan, B.; Guo, X.; Finkelman, R.B. Leachability of hazardous trace elements from entrained-flow coal gasification residues in Ningdong, China. Energy Fuels 2017, 31, 9703-9716. [CrossRef]

40. Tang, Y.; Guo, X.; Qiang, X.; Finkelman, R.B.; Han, S.C.; Huan, B.B.; Pan, X. Petrological characteristics and trace element partitioning of gasification residues from slagging entrained-flow gasifiers in Ningdong, China. Energy Fuels 2018, 32, 3052-3067. [CrossRef] 
41. ASTM International. Test Method for Moisture in the Analysis Sample of Coal and Coke; ASTM D3173-11; ASTM International: West Conshohocken, PA, USA, 2011.

42. ASTM International. Test Method for Ash in the Analysis Sample of Coal and Coke from Coal; ASTM D3174-11; ASTM International: West Conshohocken, PA, USA, 2011.

43. ASTM International. Test Method for Volatile Matter in the Analysis Sample of Coal and Coke; ASTM D3175-11; ASTM International: West Conshohocken, PA, USA, 2011.

44. ASTM International. Test Method for Total Sulfer in the Analysis Sample of Coal and Coke from Coal; ASTM D3177-02; ASTM International: West Conshohocken, PA, USA, 2011.

45. ASTM International. Test Methods for Instrumental Determination of Carbon, Hydrogen and Nitrogen in Laboratory Samples of Coal; ASTM D5373-08; ASTM International: West Conshohocken, PA, USA, 2011.

46. ASTM International. Standard Practice for Preparing Coal Samples for Microscopical Analysis by Reflected Light; ASTM D2797M-11a; ASTM International: West Conshohocken, PA, USA, 2011.

47. Dai, S.; Liu, J.; Ward, C.R.; Hower, J.C.; French, D.; Jia, S.; Hood, M.M.; Garrison, T.M. Mineralogical and geochemical compositions of Late Permian coals and host rocks from the Guxu Coalfield, Sichuan Province, China, with emphasis on enrichment of rare metals. Int. J. Coal Geol. 2016, 166, 71-95. [CrossRef]

48. Dai, S.; Wang, X.; Zhou, Y.; Hower, J.C.; Li, D.; Chen, W.; Zhu, X.; Zou, J. Chemical and mineralogical compositions of silicic, mafic and alkali tonsteins in the late Permian coals from the Songzao Coalfield, Chongqing, Southwest China. Chem. Geol. 2011, 282, 29-44. [CrossRef]

49. Standardization Administration of the People's Republic of China. Classification for Quality of Coal; Part 1: Ash, 1994; Chinese Standard GB/T 15224, 1-1994; Standardization Administration of the People's Republic of China: Beijing, China, 1994. (In Chinese)

50. Standardization Administration of the People's Republic of China. Classification for Quality of Coal; Part 2: Sulfur, 2010; Chinese Standard GB/T 15224, 2-2010; Standardization Administration of the People's Republic of China: Beijing, China, 2011. (In Chinese)

51. Kim, A.G.; Kazonich, G. The Silicate/non-silicate distribution of metals in fly ash and its effect on solubility. Fuel 2004, 83, 2285-2292. [CrossRef]

52. Ward, C.R. Analysis, origin and significance of mineral matter in coal: An updated review. Int. J. Coal Geol. 2016, 165, 1-27. [CrossRef]

53. Matjie, R.H.; Van Alphen, C. Mineralogical features of size and density fractions in Sasol coal gasification ash, South Africa and potential by-products. Fuel 2008, 87, 1439-1445. [CrossRef]

54. Matjie, R.H.; Li, Z.; Ward, C.R.; French, D. Chemical composition of glass and crystalline phases in coarse coal gasification ash. Fuel 2008, 87, 857-869. [CrossRef]

55. Reifenstein, A.P.; Kahraman, H.; Coin, C.D.A.; Calos, N.J.; Miller, G.; Uwins, P. Behaviour of selected minerals in an improved ash fusion test: Quartz, potassium feldspar, sodium feldspar, kaolinite, illite, calcite, dolomite, siderite, pyrite and apatite. Fuel 1999, 78, 1449-1461. [CrossRef]

56. Dai, S.; Ren, D.; Chou, C.-L.; Finkelman, R.B.; Seredin, V.V. Geochemistry of trace elements in Chinese coals: A review of abundances, genetic types, impacts on human health and industrial utilization. Int. J. Coal Geol. 2012, 94, 3-21. [CrossRef]

57. Ketris, M.P.; Yudovich, Y.E. Estimations of Clarkes for carbonaceous biolithes: World averages for trace element contents in black shales and coals. Int. J. Coal Geol. 2009, 78, 135-148. [CrossRef]

58. Dai, S.; Chekryzhov, I.Y.; Seredin, V.V.; Nechaev, V.P.; Graham, I.T.; Hower, J.C.; Ward, C.R.; Ren, D.; Wang, X. Metalliferous coal deposits in East Asia (Primorye of Russia and South China): A review of geodynamic controls and styles of mineralization. Gondwana Res. 2016, 29, 60-82. [CrossRef]

59. Seredin, V.V.; Finkelman, R.B. Metalliferous coals: A review of the main genetic and geochemical types. Int. J. Coal Geol. 2008, 76, 253-289. [CrossRef]

60. Sua'rez-Ruiz, I.; Ward, C.R. Chapter 4-Coal Combustion. In Applied Coal Petrology; Suárez-Ruiz, I., Crelling, J.C., Eds.; Elsevier: Amsterdam, The Netherlands, 2008; pp. 84-117.

61. Helble, J.J.; Mojtahedi, W.; Lyyränen, J. Trace element partitioning during coal gasification. Fuel 1996, 75, 931-939. [CrossRef]

62. Meij, R. Trace element behavior in coal-fired power plants. Fuel Process. Technol. 1994, 39, 199-217. [CrossRef]

63. Duchesne, M.A.; Hughes, R.W. Partitioning of inorganic elements in pilot-scale and demonstration-scale entrained-flow gasifiers. Fuel 2014, 127, 219-227. [CrossRef] 
64. Duan, L.; Sun, H.; Jiang, Y.; Anthony, E.J.; Zhao, C. Partitioning of trace elements, As, Ba, Cd, Cr, Cu, Mn and $\mathrm{Pb}$, in a $2.5 \mathrm{MW}$ th pilot-scale circulating fluidised bed combustor burning an anthracite and a bituminous coal. Fuel Process. Technol. 2016, 146, 1-8. [CrossRef]

65. Wagner, N.J.; Coertzen, M.; Matjie, R.H.; Dyk, J. Chapter 5-Coal Gasification. In Applied Coal Petrology; Suárez-Ruiz, I., Crelling, J.C., Eds.; Elsevier: Amsterdam, The Netherlands, 2008; pp. 119-144.

66. Yudovich, Y.E.; Ketris, M.P. Mercury in coal: A review: Part 1. Geochemistry. Int. J. Coal Geol. 2005, 62, 107-134. [CrossRef]

67. Dai, S.; Wang, X.; Seredin, V.V.; Hower, J.C.; Ward, C.R.; O’Keefe, J.M.K.; Huang, W.; Li, T.; Li, X.; Liu, H.; et al. Petrology, mineralogy and geochemistry of the Ge-rich coal from the Wulantuga Ge ore deposit, Inner Mongolia, China: New data and genetic implications. Int. J. Coal Geol. 2012, 90, 72-99. [CrossRef]

68. Finkelman, R.B. Modes of occurrence of potentially hazardous elements in coal: Levels of confidence. Fuel Process. Technol. 1994, 39, 21-34. [CrossRef]

69. Swaine, D. J. Chapter 3-Mode of occurrence of trace elements in coal. In Trace Elements in Coal; Elsevier: Amsterdam, The Netherlands, 1990; Volume 13, pp. 27-49.

70. Huggins, F.E.; Huffman, G.P. How do lithophile elements occur in organic association in bituminous coals? Int. J. Coal Geol. 2004, 58, 193-204. [CrossRef]

71. Zheng, L.; Liu, G.; Chou, C.-L. Abundance and modes of occurrence of mercury in some low-sulfur coals from China. Int. J. Coal Geol. 2008, 73, 19-26. [CrossRef]

72. Gao, L.; Wang, Y.; Huang, Q.; Guo, S. Modes of occurrence and thermal stability of mercury in different samples from Guandi coal preparation plant. Fuel 2017, 200, 22-30. [CrossRef]

73. Luo, G.; Yao, H.; Xu, M.; Gupta, R.; Xu, Z. Identifying modes of occurrence of mercury in coal by temperature programmed pyrolysis. Proc. Combust Inst. 2011, 33, 2763-2769. [CrossRef]

74. Finkelman, R.B. Mode of occurrence of accessory sulfide and selenide minerals in coal. In Neuviene Congress International de Stratigraphic et de Geologic du Carbonifere. Compte Rendu; Cross, A.T., Ed.; University Press: Carbondale, IL, USA, 1985; Volume 4, pp. 407-412.

75. Dai, S.; Xie, P.; Ward, C.R.; Yan, X.; Guo, W.; French, D.; Graham, I.T. Anomalies of rare metals in Lopingian super-high-organic-sulfur coals from the Yishan Coalfield, Guangxi, China. Ore Geol. Rev. 2017, 88, 235-250. [CrossRef]

76. Dai, S.; Seredin, V.V.; Ward, C.R.; Hower, J.C.; Xing, Y.; Zhang, W.; Song, W.; Wang, P. Enrichment of U-Se-Mo-Re-V in coals preserved within marine carbonate successions: Geochemical and mineralogical data from the Late Permian Guiding Coalfield, Guizhou, China. Miner. Deposita 2015, 50, 159-186. [CrossRef]

77. Kortenski, J. Trace elements in coal ashes from Sofia Pliocene Basin. Tendencias Del Mercado Del Arte 1986, 47, 165-172.

78. Dai, S.; Wang, P.; Ward, C.R.; Tang, Y.; Song, X.; Jiang, J.; Hower, J.C.; Li, T.; Seredin, V.V.; Wagner, N.J.; et al. Elemental and mineralogical anomalies in the coal-hosted Ge ore deposit of Lincang, Yunnan, southwestern China: Key role of $\mathrm{N}_{2}-\mathrm{CO}_{2}$-mixed hydrothermal solutions. Int. J. Coal Geol. 2015, 152, 19-46. [CrossRef]

79. Dai, S.; Xie, P.; Jia, S.; Ward, C.R.; Hower, J.C.; Yan, X.; French, D. Enrichment of U-Re-V-Cr-Se and rare earth elements in the Late Permian coals of the Moxinpo Coalfield, Chongqing, China: Genetic implications from geochemical and mineralogical data. Ore Geol. Rev. 2017, 80, 1-17. [CrossRef]

80. Dai, S.; Yang, J.; Ward, C.R.; Hower, J.C.; Liu, H.; Garrison, T.M.; French, D.; O’Keefe, J.M.K. Geochemical and mineralogical evidence for a coal-hosted uranium deposit in the Yili Basin, Xinjiang, northwestern China. Ore Geol. Rev. 2015, 70, 1-30. [CrossRef]

81. Huggins, F.E.; Huffman, G.P. Modes of occurrence of trace elements in coal from XAFS spectroscopy. Int. J. Coal Geol. 1996, 32, 31-53. [CrossRef]

82. Yudovich, Y.E.; Ketris, M.P. Arsenic in coal: A review. Int. J. Coal Geol. 2005, 61, 141-196. [CrossRef]

83. Dai, S.; Zeng, R.; Sun, Y. Enrichment of arsenic, antimony, mercury and thallium in a Late Permian anthracite from Xingren, Guizhou, Southwest China. Int. J. Coal Geol. 2006, 66, 217-226. [CrossRef]

84. Kolker, A.; Palmer, C.A.; Bragg, L.J.; Bunnell, J.E. Arsenic in Coal. In U.S. Geological Survey Fact Sheet; United States Geological Survey: Reston, VA, USA, 2006; pp. 2005-3152.

85. Wu, T.; Gong, M.; Lester, E.; Wang, F.; Zhou, Z. Characterization of residual carbon from entrained-bed coal water slurry gasifiers. Fuel 2007, 86, 972-982. [CrossRef]

86. Andrews, R.; Rubel, A.; Groppo, J.; Geertsema, A. Advanced gasification by-product utilization. In Office of Scientific E Technical Information Technical Reports; Univ of Kentucky Research Fdn: Lexington, KY, USA, 2006. 
87. Wu, S.; Huang, S.; Ji, L.; Wu, Y.; Gao, J. Structure characteristics and gasification activity of residual carbon from entrained-flow coal gasification slag. Fuel 2014, 122, 67-75. [CrossRef]

88. Zhao, X.; Zeng, C.; Mao, Y.; Li, W.; Peng, Y.; Wang, T. The surface characteristics and reactivity of residual carbon in coal gasification slag. Energy Fuel 2010, 24, 91-94. [CrossRef]

89. Srinivasachar, S.; Boni, A.A. A kinetic model for pyrite transformations in a combustion environment. Fuel 1989, 68, 829-836. [CrossRef]

90. Srinivasachar, S.; Helble, J.J.; Boni, A.A. Mineral behavior during coal combustion 1. Pyrite transformations. Prog. Energy Combust. 1990, 16, 281-292. [CrossRef]

91. Hu, G.; Dam-Johansen, K.; Wedel, S.; Hansen, J.P. Decomposition and oxidation of pyrite. Prog. Energy Combust. 2006, 32, 295-314. [CrossRef]

92. Bhargava, S.K.; Garg, A.; Subasinghe, N.D. In situ, high-temperature phase transformation studies on pyrite. Fuel 2009, 88, 988-993. [CrossRef]

93. Zeng, T.; Helble, J.J.; Bool, L.E.; Sarofim, A.F. Iron transformations during combustion of pittsburgh no. 8 coal. Fuel 2009, 88, 566-572. [CrossRef]

94. Zhao, H.L.; Bai, Z.Q.; Yan, J.C.; Bai, J.; Li, W. Transformations of pyrite in different associations during pyrolysis of coal. Fuel Process. Technol. 2015, 131, 304-310. [CrossRef]

95. Dreher, G.B.; Finkelman, R.B. Selenium mobilization in a surface coal mine, Powder River Basin, Wyoming. Environ. Geol. Water Sci. 1992, 19, 155-167. [CrossRef]

96. Dai, S.; Ren, D.; Chou, C.-L.; Li, S.; Jiang, Y. Mineralogy and geochemistry of the No. 6 Coal (Pennsylvanian) in the Junger Coalfield, Ordos Basin, China. Int. J. Coal Geol. 2006, 66, 253-270. [CrossRef]

97. Finkelman, R.B. Modes of occurrence of trace elements in coal. In US Geol Surv Open-File Rep; United States Geological Survey: Reston, VA, USA, 1981; pp. 81-99.

98. Goodarzi, F. Mineralogy, elemental composition and modes of occurrence of elements in Canadian feed-coals. Fuel 2002, 81, 1199-1213. [CrossRef]

99. Hower, J.C.; Robertson, J.D. Clausthalite in coal. Int. J. Coal Geol. 2003, 53, 219-225. [CrossRef] 